\title{
ORDENAMIENTO ECOLÓGICO Y AMBIENTAL EN EL DEPARTAMENTO GENERAL OBLIGADO (Provincia de Santa Fe - Argentina)
}

\section{ECOLOGICAL AND ENVIRONMENTAL MANAGEMENT IN GENERAL OBLIGADO DEPARTMENT (Santa Fe province - Argentina)}

\author{
Prof. Patricia Perla Snaider \\ Profesora Adjunta. Cátedra Climatología. \\ Profesora Titular interina. Asignatura Seminario de Fisiografía \\ Departamento de Geografía. Facultad de Humanidades. Universidad Nacional del Nordeste \\ Prof. Néstor Eduardo Puig \\ Profesor Adjunto. Cátedra Técnicas en Geografía I. \\ Profesor Adjunto interino. Cátedra Geografía de África y Oceanía \\ Departamento de Geografía. Facultad de Humanidades. Universidad Nacional del Nordeste
}

\section{RESUMEN}

En este artículo se aplican metodologías y técnicas de Ordenamiento Ecológico y Ambiental de Tierras para la zonificación ecológica y ambiental del Departamento General Obligado en el nordeste de la Provincia de Santa Fe (República Argentina).

Para ello se elaboraron mapas - alguno de ellos a partir de imágenes satelitales - que posteriormente fueron analizados para lograr un ordenamiento territorial de las tierras del área de estudio.

La metodología que se utilizó fue la del análisis cartográfico de diversas variables, tales como "vegetación", "tipos de suelo", "aptitud del suelo" y "uso del suelo". A su vez, esta última variable fue estudiada en dos momentos diferentes: "uso del suelo para el año 1986" y "uso del suelo para el año 1998". Se obtuvieron nuevos mapas mediante el análisis, la interpretación y la comparación de las variables seleccionadas: mapas de Ordenación ecológica y de Ordenación ambiental.

Además, se realizó trabajo de campo y reconocimiento in situ del aprovechamiento que se hace de la tierra.

\section{PALABRAS CLAVES}

Ordenamiento ecológico; Ordenamiento ambiental; Análisis cartográfico; Departamento General Obligado.

\section{ABSTRACT}

This article applies methodologies and techniques of Land Ecological Management and Environmental for ecological and environmental zoning of General Obligado Department in north-eastern province of Santa Fe (Argentina Republic).

Maps were prepared for it - some of them based on satellite images - which were subsequently analyzed for a territorial land management in the study area.

The methodology used was the cartographic analysis of several variables, such as "vegetation", "soil types," "soil suitability" and "land use". In turn, the last variable was studied

Publicado en formato digital: Prof. Patricia Perla Snaider y Prof. Néstor Eduardo Puig. ORDENAMIENTO ECOLÓGICO Y AMBIENTAL EN EL DEPARTAMENTO GENERAL OBLIGADO (Provincia de Santa Fe Argentina). Revista Geográfica Digital. IGUNNE. Facultad de Humanidades. UNNE. Año 12. № 24 . Julio Diciembre 2015. ISSN 1668-5180 Resistencia, Chaco. 
at two different times, "land use for 1986" and "land use for 1998". New maps through the analysis, interpretation and comparison of selected variables were obtained: Ecological management and Environmental management' maps.

In addition, fieldwork and recognition was realized in situ of the utilization that is done of the land.

\section{KEY WORDS}

Ecological management; Environmental management; Cartographic analysis; General Obligado Department.

\section{SUMARIO DEL ARTÍCULO}

En lo concerniente a la estructura del informe, primeramente presenta un marco teórico referido al ordenamiento territorial, luego se proporcionan algunas consideraciones generales sobre el área de estudio, tales como su localización, las características físicas relieve, clima-, población y poblamiento y los aspectos económicos de la misma. Seguidamente se presenta la metodología mediante la cual se llevó a cabo el trabajo. Finalmente se aborda un análisis e interpretación de las variables utilizadas (vegetación, tipos de suelo, aptitud y uso del suelo); para poder obtener una relación de los elementos que caracterizan y diferencian al área estudiada y que permiten esbozar un ordenamiento socioeconómico-ecológico.

A partir de aquí están dadas las bases para establecer las conclusiones acerca de la importancia de la aplicación de esta técnica en los estudios de ordenamiento territorial de tierras. 
Revista Geográfica Digital. IGUNNE. Facultad de Humanidades. UNNE. Año 12. № 24. Julio

- Diciembre 2015. ISSN 1668-5180 Resistencia, Chaco

\section{INTRODUCCIÓN}

El Ordenamiento Territorial busca el desarrollo socioeconómico de los territorios donde se aplica y una mejora en la calidad de vida de las sociedades involucradas. Pero también procura la gestión responsable de los recursos naturales y la protección del medio ambiente, como así también la utilización racional del territorio. Entendemos así el Ordenamiento Territorial como un instrumento para plasmar las políticas socioeconómica y medioambiental desde el punto de vista geográfico. Es deseable que nuestro país se encamine hacia un modelo de desarrollo, orientado a su inserción en la economía mundial, utilizando las ventajas comparativas y competitivas con que cuenta, sin descuidar los principios de sostenibilidad y de equidad.

En ese esquema el Departamento General Obligado, en la Provincia Argentina de Santa Fe, cuenta con una posición geográfica privilegiada, con abundantes recursos naturales, especialmente para ser explotados por las actividades agropecuarias, pero que aún mantiene una interesante biodiversidad, con recursos humanos calificados y que estas fortalezas encuentran actualmente grandes oportunidades en los mercados globales.

Sin embargo, durante el siglo $X X$ se pasó de una agricultura tradicional a una agricultura moderna (D'ENTREMONT, 1997: 232); en la primera las actividades del hombre estaban en armonía con los recursos naturales, mientras que la segunda se caracteriza por obtener los mayores rendimientos económicos a costa de la utilización de nuevas técnicas agropecuarias, tales como la producción de transgénicos, el uso de fertilizantes, abonos, agroquímicos o vacunas, entre otros; que aumentan considerablemente la producción, o bien sirven para contrarrestar los avances de las malezas, insectos o enfermedades en las plantaciones de cultivos, o prevenir o eliminar la acción de parásitos, insectos y/o enfermedades en el ganado.

En la actualidad existe una gran preocupación a nivel mundial por el uso que se está haciendo de los recursos naturales y en varios países -entre ellos Costa Rica, con una situación ejemplar: "utilizan fertilizante natural basado en la mezcla de agua con ajo y chicle picante" (NARBONA, 1999)ya se está implementando lo que se denomina indistintamente agricultura biodinámica, orgánica, verde, ecológica, natural o integral. En esta nueva agricultura posmoderna la calidad de los productos, que son totalmente naturales, es la premisa fundamental. Con las prácticas agropecuarias se intenta mejorar la vida de la tierra dejando en un segundo término la rentabilidad económica, siendo esta última el objetivo principal del sistema convencional. Es decir, mientras en la agricultura convencional interesa producir mas que preservar, en la nueva agricultura esta relación se invierte, y se sostiene que preservando se puede seguir produciendo (si bien con menores rendimientos económicos) durante mucho más tiempo, practicando una producción sostenible que no comprometa la vida de los recursos naturales para las futuras generaciones.

SEPÚLVEDA y CHINCHILLA (1998) dicen al respecto: "En la actualidad, el desarrollo sostenido del medio rural ha pasado a ocupar un primer plano en la agenda política mundial [...] y es producto de un claro entendimiento de la vinculación existente entre el potenciamiento de ese sector y el proceso de desarrollo nacional, y es producto también, de la comprensión del impacto que las actividades económicas gestadas en ese medio tienen sobre la base de recursos naturales".

En este contexto, surge la necesidad de un Ordenamiento Territorial del Departamento General Obligado, como una modalidad de articulación de los procesos de ocupación y uso del territorio, localización de actividades económicas e infraestructuras de equipamiento con el manejo ambiental. El que colaborará para orientar la localización de la población, de las actividades económicas y la infraestructura física, armonizando criterios de crecimiento económico, desarrollo social y conservación del ambiente, basado en el conocimiento de las potencialidades y restricciones

Publicado en formato digital: Prof. Patricia Perla Snaider y Prof. Néstor Eduardo Puig. ORDENAMIENTO ECOLÓGICO Y AMBIENTAL EN EL DEPARTAMENTO GENERAL OBLIGADO (Provincia de Santa Fe Argentina). Revista Geográfica Digital. IGUNNE. Facultad de Humanidades. UNNE. Año 12. No 24 . Julio Diciembre 2015. ISSN 1668-5180 Resistencia, Chaco. 
especificas de cada ámbito geográfico. En esencia, responderá a las necesidades de organizar el territorio con una base ambiental explícitamente formulada para asegurar un desarrollo responsable.

De acuerdo con lo expuesto, el presente trabajo tiene por objetivos:

\section{Objetivo general}

- Aplicar metodologías y técnicas de Ordenación Ecológica y Ambiental de Tierras a la zonificación ecológica y ambiental del Departamento General Obligado, Provincia de Santa Fe, República Argentina.

\section{Objetivos específicos}

- Generar cartografía temática del Departamento General Obligado a partir de las variables consideradas apropiadas para la estimación de un ordenamiento territorial.

- Esbozar un ordenamiento socioeconómico-ecológico del Departamento General Obligado.

- Utilizar la técnica cartográfica, entendida como una herramienta significativa, para el tratamiento y estudio de los aspectos referidos al ordenamiento territorial de tierras.

- Utilizar imágenes satelitales como recurso complementario a la técnica cartográfica.

\section{ANTECEDENTES}

EI GOBIERNO DE SANTA FE (2007) ha realizado estudios diversos sobre la cantidad y ubicación geográfica del bosque nativo (monte cerrado, monte abierto y no monte) de los departamentos del Norte provincial a través de la utilización de imágenes satelitales.

El ingeniero químico Luis CERANA (1960) presenta un estudio referido a los suelos del Norte de la Provincia de Santa Fe, más específicamente de los Departamentos Vera y 9 de Julio y analiza la composición físico - química de los suelos, más que su aptitud o potencial agrícola ganadero.

Un trabajo de similares características al del presente artículo - en el que se utilizaron imágenes satelitales LANDSAT - se realizó para llevar adelante un estudio fisiográfico de un sector de la llanura pampeana en la provincia de Santa Fe, en las inmediaciones de la ciudad de Rosario. A través de esta experiencia pretendían evaluar las posibilidades y limitaciones de las imágenes LANDSAT en su interpretación visual (Cfr. CANOBA, 1981).

Por otra parte, no sin razón, en el año 1968, los cartógrafos ya se referían a una "cartografía del futuro" que se ha iniciado con las "ciencias del espacio" y que con la ayuda de satélites la actividad cartográfica ha ingresado en una dimensión desconocida (TRUCO GRECO, 1968). Hoy en día, la tecnología satelital a la que Truco Greco hacía mención, no sólo hizo su gran aporte a la cartografía (con la imagen satelital en formato digital y en papel) sino que también contribuye con lo que se denomina Agricultura satelital o agricultura de precisión con posicionamiento satelital; ésta es una herramienta de diagnóstico y aplicación para una agricultura intensiva, en la que los mismos productores pueden hacer, por ejemplo, los mapas de rendimiento de sus propios cultivos (MACHADO, 1998).

Publicado en formato digital: Prof. Patricia Perla Snaider y Prof. Néstor Eduardo Puig. ORDENAMIENTO ECOLÓGICO Y AMBIENTAL EN EL DEPARTAMENTO GENERAL OBLIGADO (Provincia de Santa Fe Argentina). Revista Geográfica Digital. IGUNNE. Facultad de Humanidades. UNNE. Año 12. No 24 . Julio Diciembre 2015. ISSN 1668-5180 Resistencia, Chaco. 
Revista Geográfica Digital. IGUNNE. Facultad de Humanidades. UNNE. Año 12. № 24. Julio

- Diciembre 2015. ISSN 1668-5180 Resistencia, Chaco

\section{MARCO TEÓRICO}

La utilización de herramientas que permitan diagnosticar el estado de un territorio sirve de base para la toma de decisiones de manejo para la ordenación ecológica y ambiental del mismo. La ordenación Ecológica y Ambiental de Tierras exige conocer el marco conceptual de diferentes especialidades y poseer experiencia en el análisis de las interacciones entre los procesos que hacen a la dinámica del territorio. ZONNEVELD (1988) complementa estos aspectos indicando que "la integración implica, además de coordinación de ítems o temas de levantamientos seleccionados, la organización, coordinación y cooperación entre diferentes ciencias, de manera que el resultado de dicha integración es más que la mera suma de las acciones separadas".

ZONNEVELD (1988) también destaca que los paisajes deben ser considerados como una entidad holística, ya que incluye sus componentes heterogéneos, incorporando al hombre como un elemento más del conjunto. En este sentido, FORMAN y GODRON (1986) entienden al paisaje como la heterogeneidad de un área de tierra compuesta por un grupo de ecosistemas interactuantes, que se repite en forma similar a lo largo del territorio.

Los geógrafos utilizamos el término paisaje para identificar patrones individuales de territorios definidos en función de unos atributos de los elementos que lo componen y para entender la realidad espacial de forma sistémica.

El término territorio hace referencia a determinada zona del espacio terrestre administrada por el hombre. Para Milton SANTOS (1996) "la esencia del espacio es social, de ahí que el espacio sea algo más que objetos geográficos, cuyo conjunto nos da la Naturaleza". Desde este punto de vista se puede afirmar que cada fracción del espacio implica una fracción de la sociedad, por lo tanto el espacio y su territorio asociado, integra una diversidad de objetos naturales y sociales. Esto coincide con el concepto de paisaje cultural y manifiesta la necesidad de integrar los aspectos socioeconómicos en el proceso de ordenación del territorio. De esta manera, SÁNCHEZ (2001), al analizar la estructura del paisaje cultural, integra todos los tipos de construcciones humanas e incorpora sus consecuencias al introducir dinámicas generalmente más complejas que las originales (neodinámica), en las cuales se evidencian nuevos ritmos ecológicos y los impactos en la ecodinámica precedente.

En sus diversas publicaciones, SÁNCHEZ (2001; 2008; 2009) afirma que el análisis integrado de un territorio implica utilizar métodos que posibiliten estudiar integradamente las variaciones espaciales de los diferentes componentes del territorio que se desea ordenar. Es a través de estas herramientas que será factible zonificar las restricciones y potencialidades ecológicas de los recursos naturales y ordenar los condicionamientos ambientales de los diferentes paisajes frente al proceso de ocupación y desarrollo socioeconómico del territorio.

"La previsión de impactos del desarrollo requiere compatibilizar los aspectos socioeconómicos con la necesidad de sustentar la calidad ecológica de las tierras. Se trata entonces de concebir la gestión ambiental del territorio y para ello se cuenta con dos herramientas básicas que garantizan un ordenamiento territorial con fines de desarrollo sustentable: la Zonificación Ecológica (ZE) y el Ordenamiento Ambiental (OA), siendo que los principios de ambos procesamientos de los estudios ambientales puedan ser asumidos desde la perspectiva de la Ecología del Paisaje. La conceptualización de dichas herramientas requerirá en primer lugar la elaboración de un prediagnóstico ambiental basado en el análisis integrado del sistema socio-económico y el sistema ecológico" (SÁNCHEZ, 1989).

Publicado en formato digital: Prof. Patricia Perla Snaider y Prof. Néstor Eduardo Puig. ORDENAMIENTO ECOLÓGICO Y AMBIENTAL EN EL DEPARTAMENTO GENERAL OBLIGADO (Provincia de Santa Fe Argentina). Revista Geográfica Digital. IGUNNE. Facultad de Humanidades. UNNE. Año 12. No 24 . Julio Diciembre 2015. ISSN 1668-5180 Resistencia, Chaco. 
La Ordenación Ambiental se basa en cruzar la Zonificación ecológica con el uso rural de las tierras, interpretando las restricciones y potencialidades ecológicas de los sistemas paisajísticos en función de los diferentes tipos de uso, formas de ocupación y manejo de la diversidad de paisajes culturales. El resultado será el mapa de Ordenación Ambiental, el que constituirá un documento esencial para planificar la ordenación del territorio ya que integra los aspectos ecológicos de los paisajes, resultados obtenidos mediante la Zonificación ecológica con sus caracteres socioeconómicos actuales y los principales impactos ambientales del desarrollo, sobre todo aquellos que hacen a la fragilización del paisaje (SÁNCHEZ, 2005).

La importancia de la Ordenación Ambiental radica en que incorpora a los ecosistemas las relaciones "sociedad-naturaleza", ya que integra los caracteres socio-económicos con los sistemas ecológicos que les sirven de soporte, lo que facilita estudios de impactos ambientales a nivel de sistema de ocupación de las tierras.

Al respecto SÁNCHEZ (2000) expresa: “La conceptualización de unidades territoriales que anulen o minimicen conflictos asociados a externalidades que impactan negativamente sobre los sistemas ecológicos, socioeconómicos y ambientales, determina buena parte del grado de incertidumbre implícito en la planificación del desarrollo. Pero las externalidades forman parte inevitable de la complejidad del mundo y de la vida, siendo en ellas, y principalmente en su margen de imprevisibilidad, donde reside esa especie de árbitro que confiere cierta debilidad a la programación del desarrollo. Esta consideración crea cierta incertidumbre frente a la expectativa de alcanzar los objetivos y las metas del ordenamiento territorial".

Para SÁNCHEZ (2009), la idea de Ordenación Territorial constituye un proceso sistémico en el que se privilegia el análisis de las relaciones e interacciones entre la diversidad de elementos espaciales y la búsqueda de su optimización ambiental, contemplando el manejo integrado de los recursos naturales, tecnológicos y socioculturales.

SÁNCHEZ (2009) sostiene que el Ordenamiento Territorial es una importante herramienta para los estudios de desarrollo dirigidos a la construcción de escenarios y formas de vida que evidencien aproximaciones graduales a una territorialidad sustentable, ya que incorporan la dimensión ecológica y ambiental a los modelos de planificación con fines de ordenamiento territorial.

Para ello SÁNCHEZ (2009) formula un método que consiste en un proceso de ordenación e integración secuenciada de los diferentes aspectos que hacen a la estructuración de sitios y paisajes del territorio estudiado: 1) relieve y ordenación de la morfología superficial; 2) suelos y ordenación morfoedáfica; 3) vegetación y ordenación morfofitoedáfica (Ordenación Ecológica), 4) actividades humanas, impactos y ordenación socioeconómico ecológica (Ordenación ambiental).

\section{CONSIDERACIONES GENERALES SOBRE EL ÁREA DE ESTUDIO}

Antes de iniciar la exposición del trabajo en sí, se ha considerado oportuno establecer un marco general sobre aspectos relacionados con el área de estudio que se involucran, directa o indirectamente, con el tema de investigación.

El Departamento General Obligado se ubica en el extremo nordeste de la Provincia de Santa Fe (figura $N^{\circ} 1$ ) y se caracteriza por poseer singularidades que derivan de su posición geográfica, ya que se encuentra en la región denominada depresión platense y, dentro de ésta, ocupa la franja que constituye aproximadamente el límite entre la llanura pampeana y la llanura chaqueña.

Publicado en formato digital: Prof. Patricia Perla Snaider y Prof. Néstor Eduardo Puig. ORDENAMIENTO ECOLÓGICO Y AMBIENTAL EN EL DEPARTAMENTO GENERAL OBLIGADO (Provincia de Santa Fe Argentina). Revista Geográfica Digital. IGUNNE. Facultad de Humanidades. UNNE. Año 12. № 24. Julio Diciembre 2015. ISSN 1668-5180 Resistencia, Chaco. 
Figura No 1: Localización del área de estudio: Departamento General Obligado

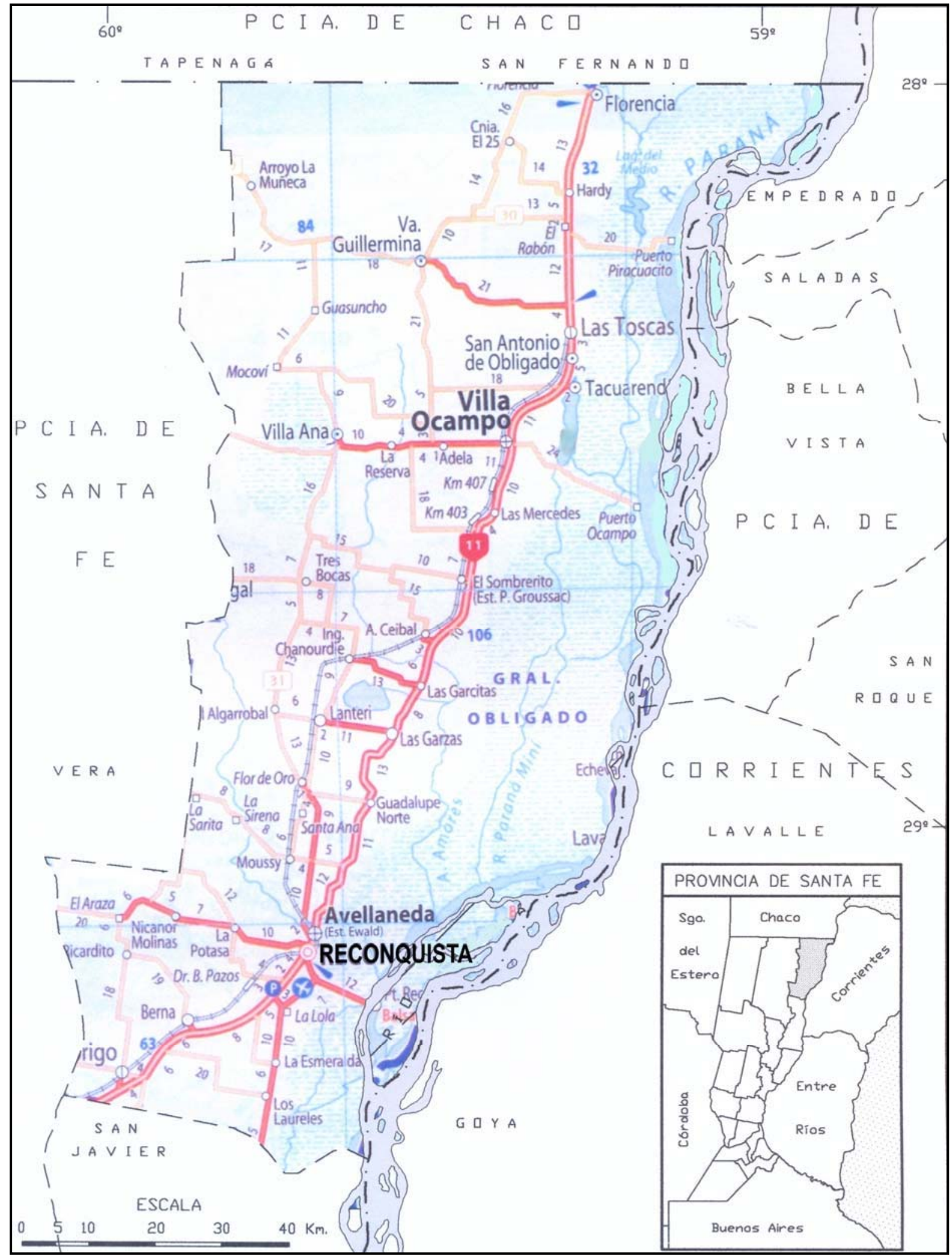

Publicado en formato digital: Prof. Patricia Perla Snaider y Prof. Néstor Eduardo Puig. ORDENAMIENTO ECOLÓGICO Y AMBIENTAL EN EL DEPARTAMENTO GENERAL OBLIGADO (Provincia de Santa Fe Argentina). Revista Geográfica Digital. IGUNNE. Facultad de Humanidades. UNNE. Año 12. № 24. Julio Diciembre 2015. ISSN 1668-5180 Resistencia, Chaco. 
Revista Geográfica Digital. IGUNNE. Facultad de Humanidades. UNNE. Año 12. No 24. Julio - Diciembre 2015. ISSN 1668-5180 Resistencia, Chaco

\section{a. Clima:}

El clima es subtropical subcontinental, con una temperatura media anual de $20^{\circ} \mathrm{C}$ y extremos que pueden alcanzar máximas de $40^{\circ} \mathrm{C}$ y mínimas bajo cero. Las precipitaciones medias anuales son de $1.380 \mathrm{~mm}$, concentrándose en los meses de Octubre a Abril, correspondiendo a la estación cálida. El mínimo de precipitaciones se registra durante la estación invernal, entre los meses de junio a agosto, en los que pueden presentarse ocasionales sequías y algunas heladas (BRUNIARD, 1979, 1987).

En algunos años, coincidentes con el fenómeno de El Niño, se producen intensas precipitaciones que provocan inundaciones extraordinarias en gran parte del territorio. También, pero con menor frecuencia, existen años en los que se acentúa y prolonga la sequía invernal, lo que favorece la ocurrencia de incendios, naturales y provocados, de pastizales y sabanas.

\section{b. Población y Poblamiento:}

Algunas de las poblaciones nacieron de misiones religiosas que intentaron evangelizar a los aborígenes surgiendo, por ejemplo, la localidad de San Antonio de Obligado; mientras que otros poblados, como Reconquista, Villa Ocampo, Las Toscas, aparecen como consecuencia del proceso de colonización e inmigración, sobre todo de españoles, italianos y alemanes.

Por otra parte, el occidente departamental estaba cubierto, en su mayoría, por los bosques de quebracho colorado, los que fueron explotados por la empresa La Forestal para la extracción de tanino $^{1}$. Los escasos pueblos de este sector, tales como Tartagal, Villa Ana (Figura No 2.A), Villa Guillermina, fueron originados a partir de la presencia de la empresa forestal. Dicha empresa, que primeramente se denominó Santa Fe Land Company fue creada hacia el año 1884 contando con casi 2 millones de hectáreas de bosque nativo que el Gobierno de la Provincia de Santa Fe le había entregado a los propietarios de la misma: Murrieta y Cía, de Londres, para saldar un empréstito que tenía con los mismos. A partir de ese momento se inicia el proceso de explotación del quebracho colorado y extracción del tanino que perduró durante ocho décadas ya que en 1963 se produjo el cierre definitivo de La Forestal (The Forestal Land, Timber and Railways Company Limited). Actualmente, sólo existen algunos relictos de quebracho, de entre 30 y 50 años, que lograron sobrevivir a partir del momento en que los ingleses se marcharon.

\section{c. Economía:}

Lo que hace 100 años fue una actividad económica resplandeciente, hoy la explotación forestal prácticamente no existe en esta región (menos aún la del quebracho colorado) ya que fue paulatinamente sustituida por el desarrollo de la producción de caña de azúcar, algodón, soja, sorgo y por la cría extensiva de ganado vacuno.

La explotación de caña de azúcar (Figura № 2.C) fue creciendo con el tiempo y hasta la década del 70 el proceso de industrialización se llevó adelante en tres ingenios de la zona, ubicados en las localidades de Las Toscas $^{2}$, Tacuarendí ${ }^{3}$ y Villa Ocampo ${ }^{4}$. Durante algunas zafras entre las

\footnotetext{
${ }^{1}$ El Tanino es una substancia astringente que se encuentra en algunos productos vegetales y se emplea generalmente para curtir las pieles. (GARCÍA-PELAYO y GROSS, 1992: 977).

${ }^{2}$ Hasta hace aproximadamente 25 años este ingenio pertenecía a la firma Welbers S. A. y luego fue comprado por la Cooperativa Agropecuaria Las Toscas Ltda. Actualmente su propietario es el tosquense Romelio Snaider.

${ }^{3}$ Hacia mediados de la década del 70 este ingenio, perteneciente a la firma Sardáa \& Goitía, fue desmantelado y en la actualidad se encuentra la Papelera Yapur S. A.
}

Publicado en formato digital: Prof. Patricia Perla Snaider y Prof. Néstor Eduardo Puig. ORDENAMIENTO ECOLÓGICO Y AMBIENTAL EN EL DEPARTAMENTO GENERAL OBLIGADO (Provincia de Santa Fe Argentina). Revista Geográfica Digital. IGUNNE. Facultad de Humanidades. UNNE. Año 12. No 24 . Julio Diciembre 2015. ISSN 1668-5180 Resistencia, Chaco. 
décadas de 1960 y 1980 también se trasladaba parte de la producción cañera al Ingenio de Las Palmas, en la Provincia del Chaco. Actualmente son los Ingenios de Las Toscas y Arno de Villa Ocampo los que se ocupan de realizar el proceso de industrialización de la caña de azúcar.

De esta manera, la actividad agrícola comenzó a diversificarse y los monocultivos de la caña de azúcar y el algodón hoy comparten el espacio agrícola con plantaciones de soja, maíz, sorgo, girasol, y algunas forrajeras destinadas a la actividad ganadera.

Por su parte, los sectores dedicados a la ganadería se distribuyen en el occidente y oriente departamental, quienes tienen una capacidad de carga de 1 animal cada 21/2 ó 3 has (es decir, 1/3 animal por hectárea), mientras que en los campos ganaderos que se encuentran en el área agrícola, donde los suelos son mejores y los terrenos no son inundables, la capacidad de carga es de 1 animal cada 2 has ( $1 / 2$ animal por hectárea) o 1 animal por hectárea.

Figura $N^{\circ}$ 2: Ilustraciones del área de estudio (Fotografías: Snaider, Patricia)

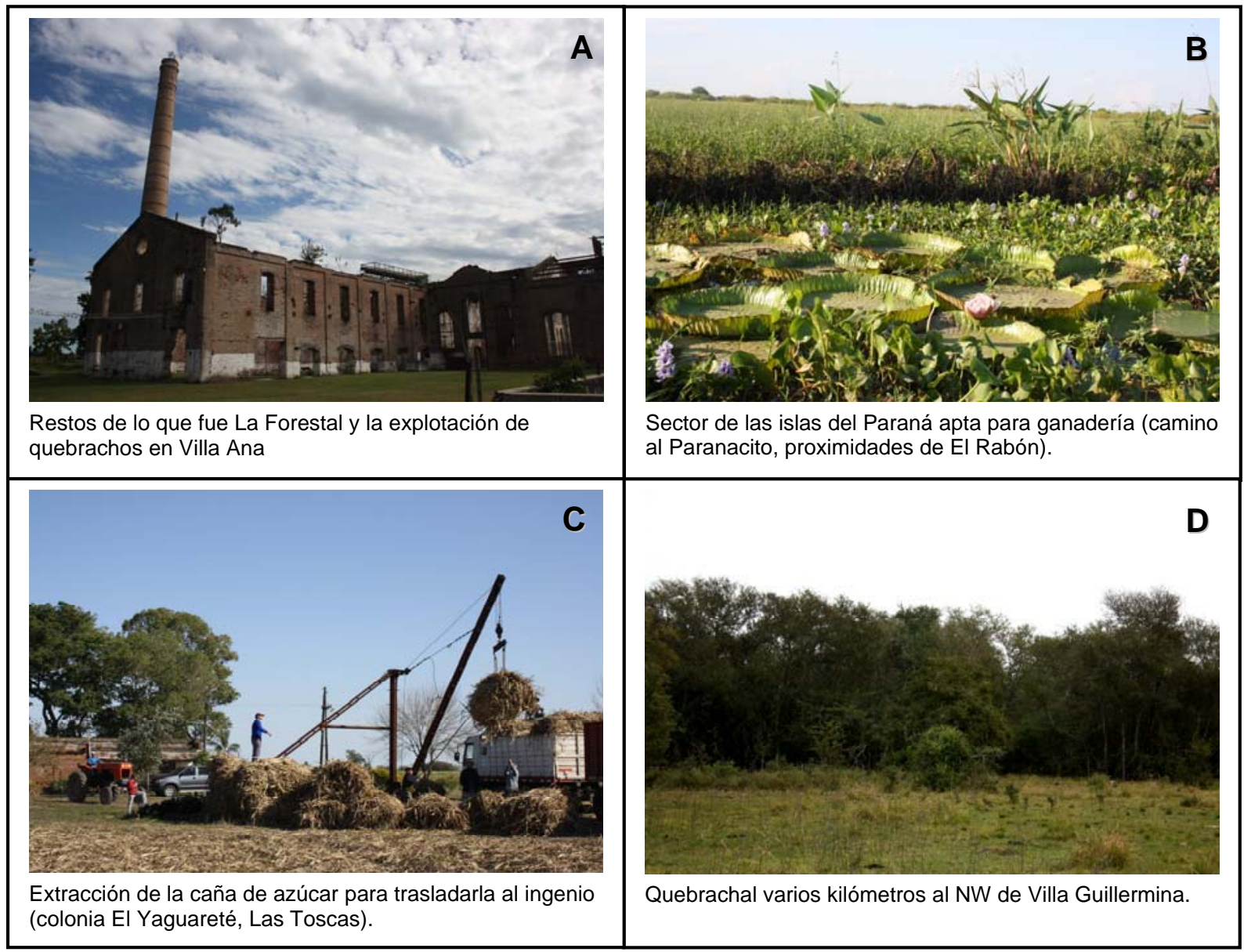

\section{MATERIALES Y METODOLOGÍA}

En los objetivos que se propusieron para el presente trabajo se insiste en la confección de mapas - alguno de ellos a partir de imágenes satelitales - y su posterior análisis para abordar un esbozo de ordenamiento territorial de las tierras del Departamento General Obligado.

${ }^{4}$ El ingenio Arno se encuentra, aún en la actualidad, en muy buenas condiciones edilicias.

Publicado en formato digital: Prof. Patricia Perla Snaider y Prof. Néstor Eduardo Puig. ORDENAMIENTO ECOLÓGICO Y AMBIENTAL EN EL DEPARTAMENTO GENERAL OBLIGADO (Provincia de Santa Fe Argentina). Revista Geográfica Digital. IGUNNE. Facultad de Humanidades. UNNE. Año 12. No 24 . Julio Diciembre 2015. ISSN 1668-5180 Resistencia, Chaco. 
La metodología que se utilizó para poder abordar nuestra unidad de análisis, el Departamento General Obligado, fue la del análisis cartográfico de la misma a través de diversas variables, tales como "vegetación", "tipos de suelo", "aptitud del suelo" y "uso del suelo". A su vez, este último atributo fue dimensionado en dos momentos diferentes: "uso del suelo para el año 1986" y "uso del suelo para el año 1998". A partir de las variables seleccionadas, y mediante la intervención de procesos tales como el análisis, la interpretación y la comparación entre ellas, se obtuvieron nuevos mapas: ordenación morfofitoedáfica (Ordenación Ecológica) y ordenación socioeconómico ecológica (Ordenación ambiental).

Para poder presentar también la distribución del uso del suelo relativamente actualizado se recurrió a las Cartas de Imagen Satelital de la República Argentina, escala 1:250.000, confeccionadas por el Instituto Geográfico Nacional (ex Militar), dependiente del Ejército Argentino. Éstas fueron captadas por la familia de satélites LANDSAT de la NASA en los que se emplean los sensores MT (Thematic Mapper). Cabe aclarar que el proceso de diferenciación de áreas con distintos usos de la tierra en la imagen satelital se realizó de manera manual a través de la interpretación visual de la imagen $^{5}$.

Además, se realizó trabajo de campo mediante el reconocimiento in situ del aprovechamiento que se hace de la tierra. De esta manera, se tomó contacto directo con parte del área de estudio y se verificaron algunos de los sectores identificados en la imagen satelital ${ }^{6}$.

A través de la interpretación de la correspondencia espacial entre la distribución de las variables analizadas, es decir, visualizando las áreas de coincidencia - o de ausencia de la misma se identificaron sectores donde el uso del suelo es sustentable y otras áreas donde no lo es. Una vez obtenidos los resultados del análisis, se arriba al proceso de descripción e interpretación o, lo que es igual, a la etapa literaria, para lo cual se elabora el presente artículo.

El software utilizado para la confección de los mapas y la digitalización del material cartográfico recopilado fue ArcGIS 9.2 y no deben dejar de mencionarse algunos de los inconvenientes que se presentaron en la elaboración de los mismos:

El material cartográfico recopilado se encuentra a diferentes escalas y, por lo tanto, el nivel de detalle de la información consignada en cada uno es variado.

Al pertenecer a diferentes fuentes y tener escalas y sistemas de proyección desiguales hubieron inconvenientes de desfasaje de las áreas cartografiadas.

No se contó con toda la cartografía necesaria para poder aplicar esta metodología, como por ejemplo: inexistencia de mapa geomorfológico o de relieve y de vegetación con el mismo nivel de detalle de los demás.

\section{RESULTADOS: ANÁLISIS DE LAS VARIABLES}

Los mapas y las imágenes satelitales, complementados con trabajo de campo, constituyen la herramienta por excelencia del proceso de planificación territorial, ya que permiten incorporar tanto

\footnotetext{
${ }^{5}$ Sobre un papel transparente se dibujaron las áreas que fueron diferenciadas luego de la observación y lectura de la carta imagen, las que posteriormente se digitalizaron.

${ }^{6}$ Durante la actividad de "reconocimiento a campo" se tomaron diversas fotografías, en las que es posible identificar el uso que se hace de la tierra en cada uno de los sitios reconocidos. Algunas fotografías son presentadas en la figura $\mathrm{N}^{\circ} 2$.
}

Publicado en formato digital: Prof. Patricia Perla Snaider y Prof. Néstor Eduardo Puig. ORDENAMIENTO ECOLÓGICO Y AMBIENTAL EN EL DEPARTAMENTO GENERAL OBLIGADO (Provincia de Santa Fe Argentina). Revista Geográfica Digital. IGUNNE. Facultad de Humanidades. UNNE. Año 12. № 24 . Julio Diciembre 2015. ISSN 1668-5180 Resistencia, Chaco. 
las variables que interactúan en el espacio geográfico, como aquellas que son cualitativas. Por lo tanto, "se consideran instrumentos de consulta obligatoria, ágil y útil para la toma de decisiones en el campo del manejo integrado de recursos naturales" (ROMERO \& SEPÚLVEDA, 1999). Se abordará, a partir de aquí, el análisis, interpretación y descripción de las variables utilizadas para este trabajo.

\section{Relieve:}

La composición geológica del Chaco santafesino hasta unos cien metros de profundidad está integrada por varias formaciones sedimentarias cuaternarias depositadas sobre un sustrato marino mioceno (Fm Paraná). Dichas formaciones cuaternarias son loessicas en el Oeste, palustres en las zonas centrales y fluviales en el Este.

En la porción occidental del departamento, correspondiente a los bajos submeridionales (dentro de la eco-región del Chaco Húmedo según la figura $N^{\circ} 3$ ), se desarrolla una llanura poligénica sujeta a modelado fluvial y eólico, a veces superpuesto, con escasa pendiente hacia el Sureste, alrededor de $10 \mathrm{~cm}$ por $\mathrm{km}$, en el que la red de escurrimiento es poco definida. Acorde con ello, se producen escurrimientos mantiformes y acumulaciones de agua en superficie durante los períodos húmedos. Ese escurrimiento mantiforme termina siendo drenado hacia el Paraná a través del sistema de esteros y bañados denominado Las Golondrinas. Los elementos modeladores actuales del paisaje son: la erosión eólica, la erosión hídrica, el proceso de disolución química de evaporitas llamados "pseudokarst" y los incendios.

Hacia el Oriente, dentro de la Ecoregión Delta e Islas del Paraná (figura №3), encontramos un conjunto de macrosistemas de humedales de origen fluvial que, encajonado en una gran falla geológica que se extiende en sentido Norte-Sur, constituye una típica llanura aluvial sometida al control ecológico del sistema fluvial del Paraná. La terraza baja se inunda regularmente, mientras que la terraza alta presenta una frecuencia de inundación irregular y dependiendo de crecientes extraordinarias. Sobre la margen derecha del Paraná se suceden áreas altas y bajas inundables con meandros antiguos y nuevos, grandes cañadas, cauces abandonados, esteros, bañados (Figura $\mathrm{N}^{\circ}$ 2.B), pantanos y lagunas que conforman una intrincada red de ríos y riachos.

El valle aluvial propiamente dicho se halla constituido por el canal principal del río, sus brazos laterales (semipermanentes o esporádicos), los relieves altos relativos (albardones), las medias lomas altas y bajas (espiras) y los bajos (esteros y lagunas semilunares). Estos últimos dominan el paisaje y se inundan regularmente. En los amplios interfluvios deprimidos se presentan riachos de drenaje pobre, anegables y en algunos casos con sales y sodio. También encontramos dos tipos de lagunas: cuerpos de aguas estancadas en las partes bajas y grandes lagunas en antiguos cursos fluviales hoy abandonados (estrangulamiento de meandros, captaciones, etc.).

Separando ambos ambientes se encuentra el Lomo sudchaqueño-santafecino, llamado también dorsal agrícola paranaense (MORELLO y ADAMOLI, 1974), el que se levanta con dirección submeridiana sobre un pilar tectónico flanqueado por dos sistemas de fallas, uno oriental, que lo separa del valle del Paraná y otra occidental que lo separa de los bajos submeridionales. Se caracteriza por un relieve levemente convexo, que contrasta con la horizontalidad de las unidades vecinas. Posee redes hidrográficas bien definidas; conformadas por cuencas estrechas y largas que se alinean paralelamente y que doblan hacia el Este el atravesar esta dorsal (Figura $N^{0} 4$ ).

Puede observarse erosión vinculada a los bordes de los valles y a las cunetas de los caminos. En algunos lugares también se pueden producir cárcavas de hasta 2 ó 3 metros de profundidad. Las áreas centrales de los interfluvios tienen una pendiente suave sin erosión visible.

Publicado en formato digital: Prof. Patricia Perla Snaider y Prof. Néstor Eduardo Puig. ORDENAMIENTO ECOLÓGICO Y AMBIENTAL EN EL DEPARTAMENTO GENERAL OBLIGADO (Provincia de Santa Fe Argentina). Revista Geográfica Digital. IGUNNE. Facultad de Humanidades. UNNE. Año 12. No 24 . Julio Diciembre 2015. ISSN 1668-5180 Resistencia, Chaco. 
Figura No 3: Eco-Regiones de la Argentina

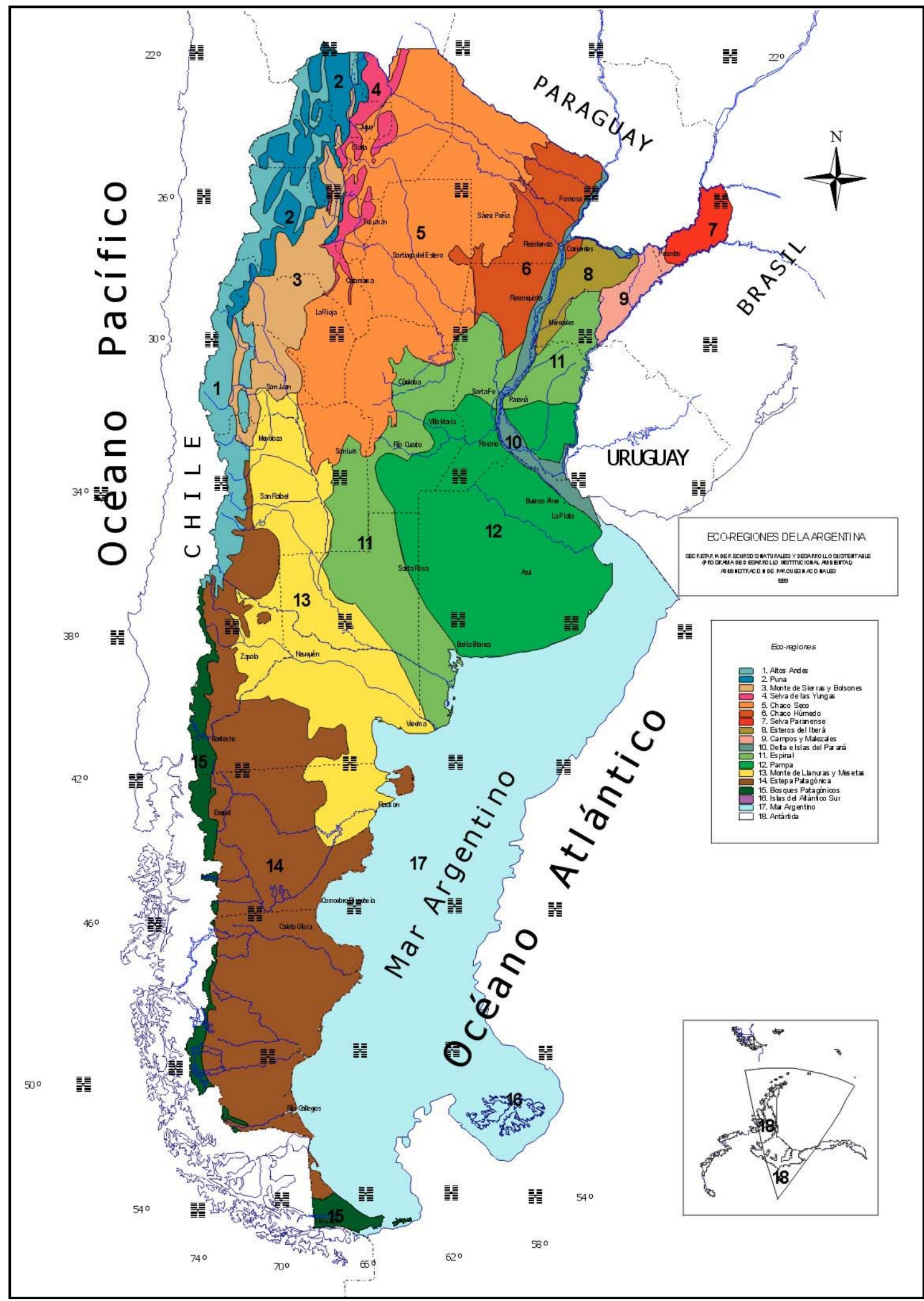

Publicado en formato digital: Prof. Patricia Perla Snaider y Prof. Néstor Eduardo Puig. ORDENAMIENTO ECOLÓGICO Y AMBIENTAL EN EL DEPARTAMENTO GENERAL OBLIGADO (Provincia de Santa Fe Argentina). Revista Geográfica Digital. IGUNNE. Facultad de Humanidades. UNNE. Año 12. № 24. Julio Diciembre 2015. ISSN 1668-5180 Resistencia, Chaco. 
Figura No 4: Relieve del Departamento General Obligado

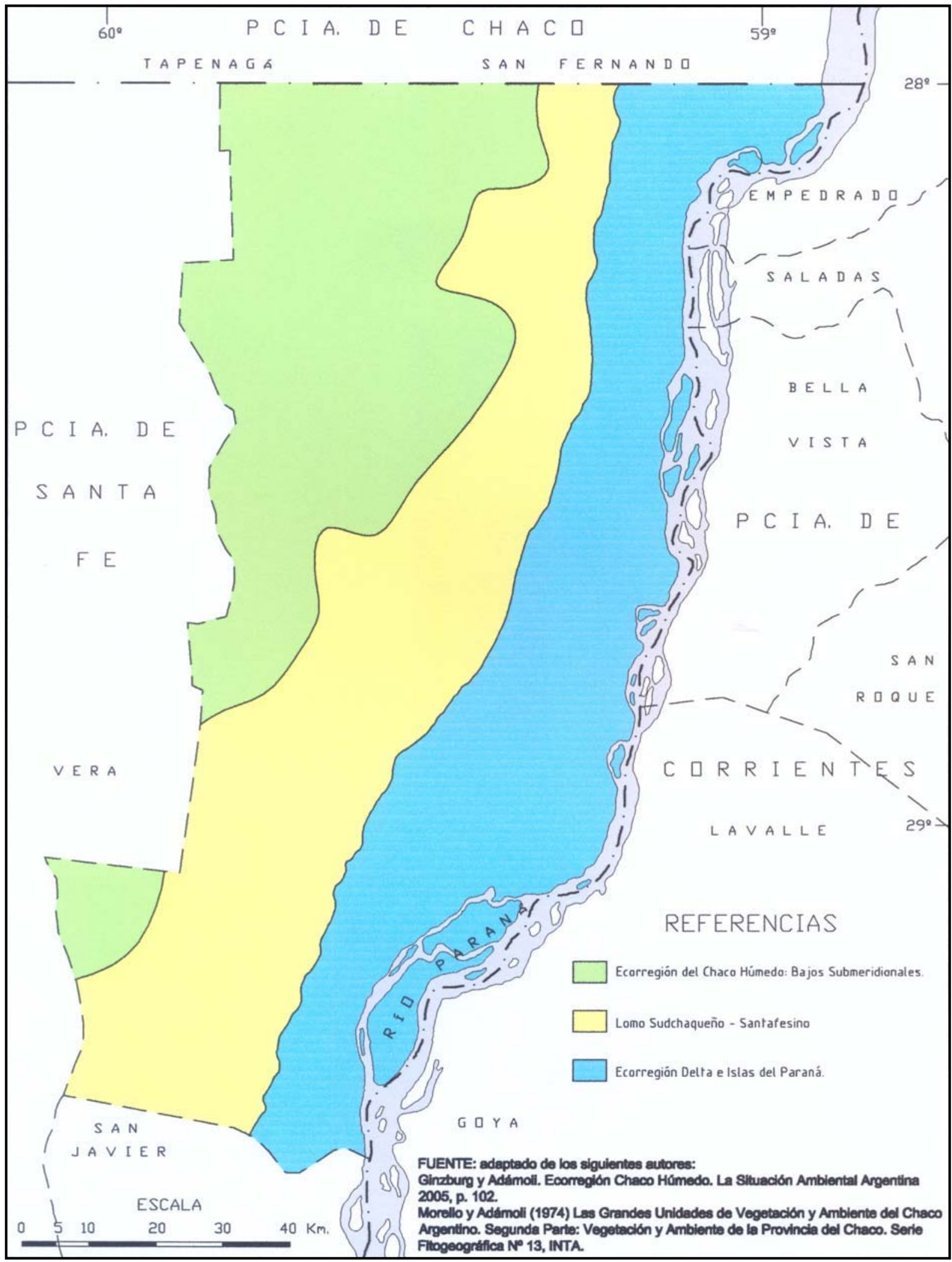

Publicado en formato digital: Prof. Patricia Perla Snaider y Prof. Néstor Eduardo Puig. ORDENAMIENTO ECOLÓGICO Y AMBIENTAL EN EL DEPARTAMENTO GENERAL OBLIGADO (Provincia de Santa Fe Argentina). Revista Geográfica Digital. IGUNNE. Facultad de Humanidades. UNNE. Año 12. № 24. Julio Diciembre 2015. ISSN 1668-5180 Resistencia, Chaco. 
Revista Geográfica Digital. IGUNNE. Facultad de Humanidades. UNNE. Año 12. № 24. Julio

- Diciembre 2015. ISSN 1668-5180 Resistencia, Chaco

\section{Vegetación:}

El área de estudio se vertebra a lo largo de la mayor parte de la Cuña Boscosa Santafesina, encontrando al Oriente la Planicie de inundación del río Paraná y parte de los Bajos Submeridionales al occidente (Figura $\mathrm{N}^{\circ} 5$ ).

\section{Cuña Boscosa Santafesina:}

Los bosques de la Cuña Boscosa presentan una notable heterogeneidad estructural y florística, atribuidos a diferencias espaciales en la topografía, el tipo de suelo y los regímenes de incendios, de pastoreo y de explotación forestal (MORELLO, 1970; MORELLO y ADÁMOLI, 1974).

A escala paisajística podemos decir que en las partes altas encontramos bosques densos mixtos, a alturas intermedias hay bosques abiertos de S. balansae (quebrachales, ver figura $N^{\circ} 2 . D$ ) y en los valles hay sabanas de Prosopis nigra (algarrobales) o Copernicia alba (palmares) que flanquean a la vegetación herbácea higrófila de los valles. Dentro de un quebrachal, la estructura del bosque varía marcadamente en distancias de decenas de metros en relación con diferencias de microrelieve y humedad del suelo. Las áreas con relieve convexo tienen mayor densidad de plantas leñosas, mayor proporción de arbustos y menor proporción de individuos con hojas compuestas o con espinas que las áreas planas. También encontramos dos especies de bromeliáceas terrestres, Bromelia serra y Aechmea distichantha, las que forman colonias de varios metros de sección en el sotobosque que se alternan con parches sin bromeliáceas. Las áreas planas asociadas con suelos húmedos contienen menor diversidad de especies leñosas y mayor proporción de plantas con hojas pequeñas que las asociadas con suelos secos.

\section{Bajos Submeridionales:}

La característica principal de su vegetación es la escasez de árboles. Más de tres cuartos están cubiertos por sabanas de gramíneas, principalmente por espartillares con palmares caranday y ejemplares de ñandubay y espinillo en forma desperdigada. Existen algunas comunidades leñosas como palmares, chañares, algarrobos y en menor medida, quebrachos colorados que marcan la transición hacia la Cuña Boscosa santafesina. Otro rasgo particular de la zona es la presencia de lagunas permanentes y esteros vegetados, generalmente ocupados por juncos y totoras.

\section{Planicie de Inundación del Río Paraná:}

Forma parte de la eco-región Delta e Islas del Paraná (GRINZBURG y ADÁMOLI, 2005) y comprende el valle de inundación del río Paraná. Incluye islas bajas e inundables que se distribuyen a lo largo del curso del Paraná.

En las riberas existen bosques de ceibos, sauces, alisos, timbó, curupí, palmeras pindó, canelón, higuerón y arrayán; en las zonas más altas se instala un bosque abierto moderadamente denso de espinillo.

Sobre los albardones más desarrollados se extienden, formando una estrecha franja, las selvas en galería con un reducido desarrollo lateral (también llamadas selvas marginales, selvas de ribera o bosques de albardón). Estos albardones cuando tienen un alto relieve positivo permiten la instalación de especies leñosas que no pueden prosperar en las áreas inundables en los que abundaban árboles de timbó blanco (Cathormium polyantum), ibirá pitá (Peltophorum dubium), lapacho (Tabebuia impetiginosa), Francisco Álvarez (Pisonia zapallo) y palo mora (Chlorophora tinctorea); y sobre sus márgenes y en los albardones menos desarrollados crece un bosque hidrófilo, llamado monte blanco formado por sauces y ceibos.

Publicado en formato digital: Prof. Patricia Perla Snaider y Prof. Néstor Eduardo Puig. ORDENAMIENTO ECOLÓGICO Y AMBIENTAL EN EL DEPARTAMENTO GENERAL OBLIGADO (Provincia de Santa Fe Argentina). Revista Geográfica Digital. IGUNNE. Facultad de Humanidades. UNNE. Año 12. No 24. Julio Diciembre 2015. ISSN 1668-5180 Resistencia, Chaco. 
Figura No 5: Vegetación del Departamento General Obligado

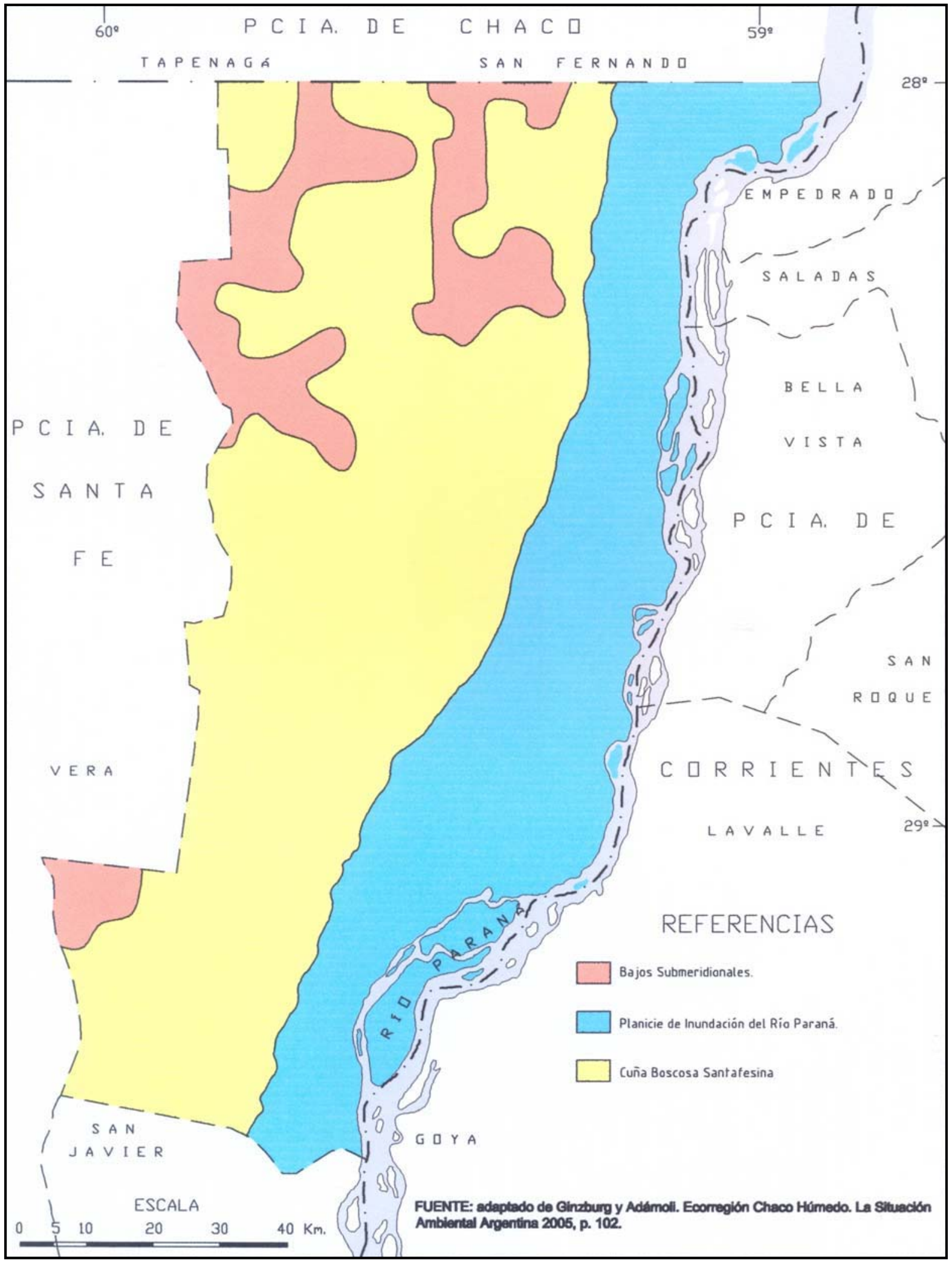

Publicado en formato digital: Prof. Patricia Perla Snaider y Prof. Néstor Eduardo Puig. ORDENAMIENTO ECOLÓGICO Y AMBIENTAL EN EL DEPARTAMENTO GENERAL OBLIGADO (Provincia de Santa Fe Argentina). Revista Geográfica Digital. IGUNNE. Facultad de Humanidades. UNNE. Año 12. № 24. Julio Diciembre 2015. ISSN 1668-5180 Resistencia, Chaco. 
Las medias lomas altas son dominadas por arbustales de espinillos mansos y carpincheras (Mimosa spp.); y las bajas por pajonales de distinto tipo: carrizales (Panicum grumosum), pirizales (Cyperus giganteus), achirales (Thalia geniculata), canutillares (Paspalum repens), etc. Los bajos se hallan cubiertos por pajonales y pastizales dominados por totoras (Thypa dominguensis), catay (Polygonum punctatum), verdolaga (Ludwigia peploides) y camalotes (Eichhornia spp. y Pontederia spp.) (Ver figura $\mathrm{N}^{\circ}$ 2.B).

\section{Tipos de suelo:}

Según el INTA (1990: 3), "el conocimiento de los suelos, de sus características y propiedades, así como de sus potencialidades y limitaciones es fundamental para poder emitir juicios sobre el uso y manejo de la tierra." Para la representación del mapa con los tipos de suelo se utilizaron los datos del Atlas de Suelos de la República Argentina y del Mapa de Suelos de la Provincia de Santa Fe (ESPINO et al., 1983) y el Sistema de clasificación de los suelos utilizado es el norteamericano "Soil Taxonomy", ya que se adecua a las necesidades de nuestro país y ha sido adoptado por la mayoría de los edafólogos argentinos (figura $N^{\circ} 6$ ).

En el cuadro que se presenta a continuación aparecen, de manera esquemática, los tipos de suelo representados en la cartografía (cuadro $N^{0} 1$ ), los cuales se describen según los órdenes, subórdenes, grandes grupos y subgrupos.

Cuadro $N^{\circ}$ 1: Tipos de suelo

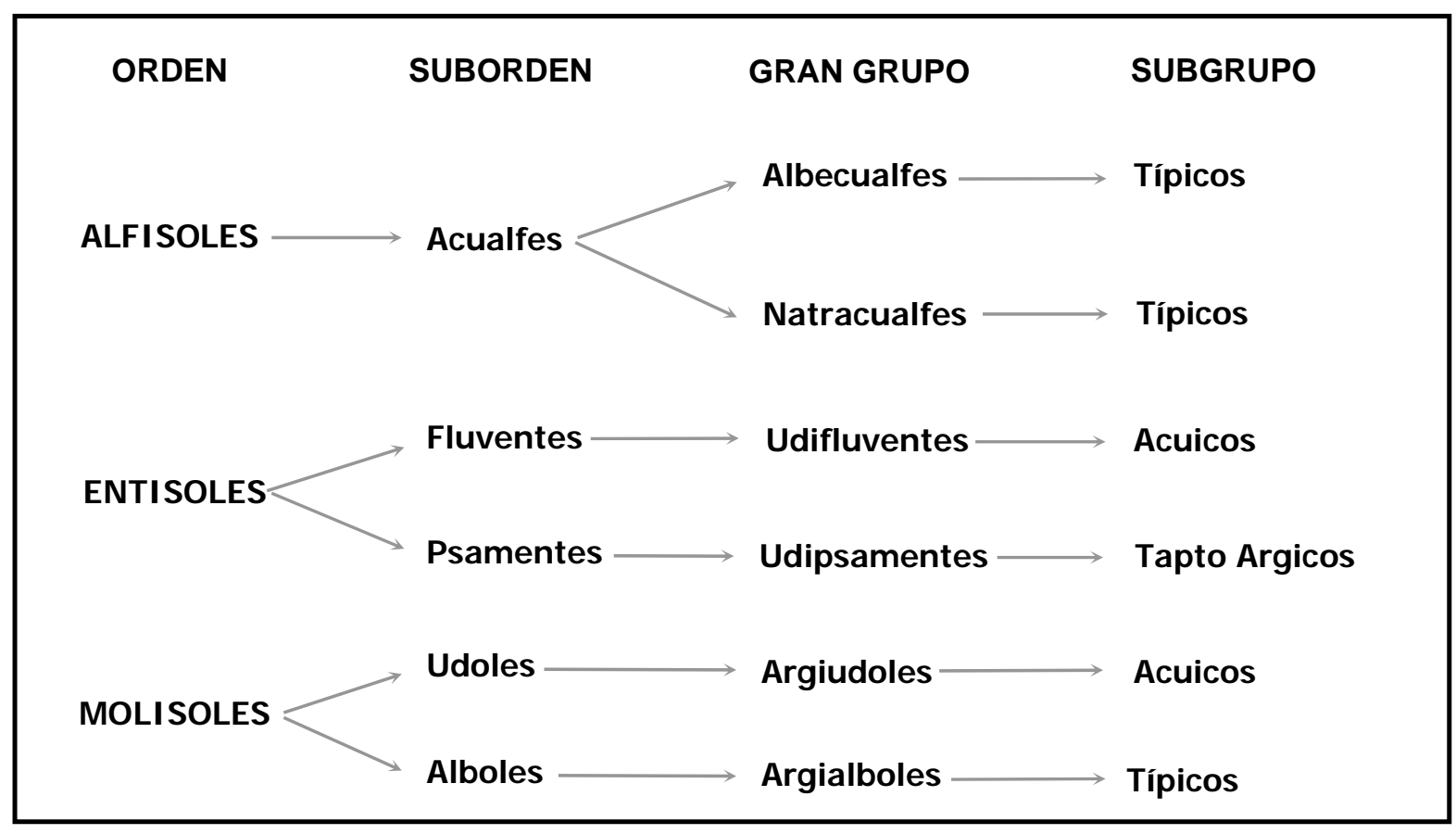

\section{A. Alfisoles:}

Se caracterizan por presentar un horizonte superficial pobre en materia orgánica y de poco espesor.

ACUALFES: están estacionalmente saturados con agua por períodos prolongados y asociados, por lo general, con una capa de agua freática fluctuante y cercana a la superficie ocasionando una falta de oxigenación que afecta cíclicamente la zona de crecimiento radicular. Normalmente, este tipo de suelos se localiza en áreas planas o depresiones que durante la época lluviosa están expuestas a un encharcamiento debido al escaso escurrimiento superficial y al aporte

Publicado en formato digital: Prof. Patricia Perla Snaider y Prof. Néstor Eduardo Puig. ORDENAMIENTO ECOLÓGICO Y AMBIENTAL EN EL DEPARTAMENTO GENERAL OBLIGADO (Provincia de Santa Fe Argentina). Revista Geográfica Digital. IGUNNE. Facultad de Humanidades. UNNE. Año 12. No 24 . Julio Diciembre 2015. ISSN 1668-5180 Resistencia, Chaco. 
de aguas de escorrentía de las zonas circundantes más elevadas. Dentro del departamento objeto de estudio se han encontrado los siguientes Grandes Grupos:

AAtc Albacualfes típicos: son suelos de color gris parduzco claro, limosos y de estructura granular fina. Se ubican en relieves planos y presentan una escasa aptitud agrícola y una buena capacidad forrajera. Los cultivos más frecuentes son el algodón, la caña de azúcar y el sorgo.

AEtc Natracualfes típicos: son suelos que presentan contenido de sodio (precisamente es una de sus limitaciones) y, por lo general, se debe a la muy baja permeabilidad que también ocasiona que el suelo este saturado con agua frecuentemente. Esta saturación es producida por fluctuaciones de capas de agua cercanas a la superficie y por anegamiento como consecuencia de lluvias o desbordes de ríos y arroyos. Se localizan en áreas deprimidas, con difícil escurrimiento y serios problemas de drenaje. Debido a que son periódicamente anegables, con alto contenido de sodio y sales solubles, poseen limitaciones severas de difícil solución. Se los utiliza para el desarrollo de actividades ganaderas para aprovechar la vegetación natural, aunque también se implantan pasturas resistentes a tales condiciones.

\section{E. Entisoles:}

Presentan un horizonte superficial claro, de poco espesor y escasa materia prima.

FLUVENTES: son los entisoles que se desarrollan en las planicies de inundación, derrames y deltas de los ríos y arroyos, sobre sedimentos que fueron depositados recientemente por las aguas. Por lo tanto, están afectados periódicamente por inundaciones aunque no están permanentemente saturados por el agua.

EJac Udifluventes ácuicos: se formaron sobre sedimentos depositados por el río Paraná y no tienen un buen drenaje por la presencia de la napa freática próxima a la superficie. Algunos de ellos presentan una vegetación boscosa y son utilizados para la explotación ganadera y en otros se cultivan caña de azúcar, algodón, etc. Estos suelos presentan limitaciones vinculadas a los períodos con exceso de humedad, por lo que se crean condiciones anaeróbicas restrictivas para el normal desarrollo de los cultivos, disminuyendo, de esta manera, su capacidad agrícola.

EU:ag Udipsamentes tapto árgicos: son suelos con perfiles poligenéticos que se desarrollaron sobre otro suelo preexistente, originando una discontinuidad litológica.

\section{Molisoles:}

Son suelos de color negro o pardo que se desarrollan en climas templado-húmedos a semiáridos y presentan una cobertura vegetal compuesta especialmente por gramíneas. Otra característica de los molisoles es la estructura granular que facilita el movimiento del agua y del aire. Este tipo de suelos es utilizado para la producción de alimentos y en ellos se obtienen los más altos rendimientos, no requiriendo grandes cantidades de fertilizantes para lograrlo.

ALBOLES: su horizonte esta lavado por las fluctuaciones estacionales del agua que satura el suelo durante lapsos significativos. Se lo observa en áreas planas y vías de drenaje o depresiones cóncavas, receptoras del agua proveniente de áreas próximas más elevadas.

MAtc Argialboles típicos: se hallan en cubetas, depresiones más o menos extendidas y pendientes en las áreas cercanas a las vías de escurrimiento y arroyos. No son los suelos indicados para ser utilizados con cultivos agrícolas, pero si cuentan con un horizonte superficial de espesor considerable, se los puede dedicar al cultivo de especies como el sorgo y girasol. 
Figura No 6: Tipos de suelo del Departamento General Obligado

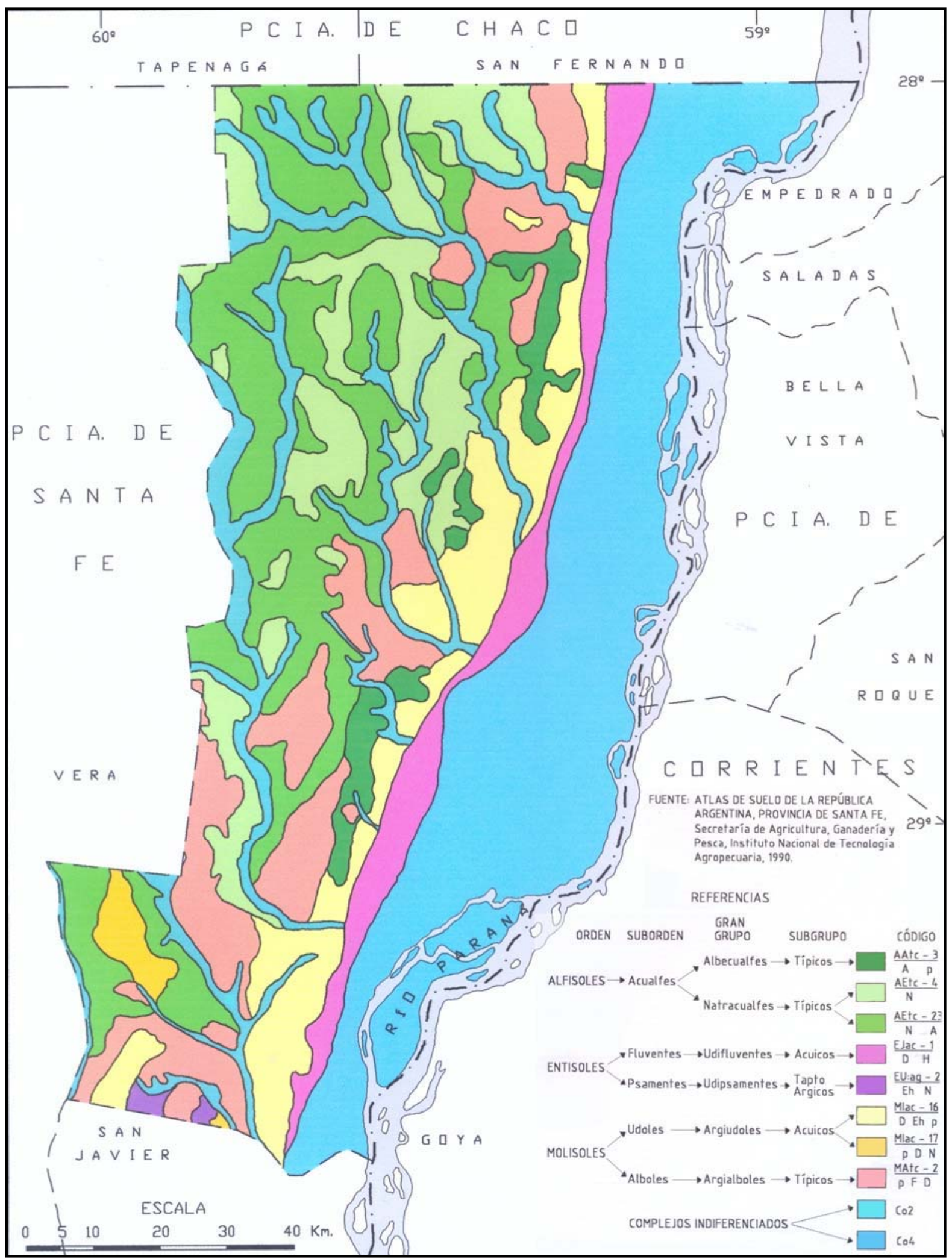

Publicado en formato digital: Prof. Patricia Perla Snaider y Prof. Néstor Eduardo Puig. ORDENAMIENTO ECOLÓGICO Y AMBIENTAL EN EL DEPARTAMENTO GENERAL OBLIGADO (Provincia de Santa Fe Argentina). Revista Geográfica Digital. IGUNNE. Facultad de Humanidades. UNNE. Año 12. № 24. Julio Diciembre 2015. ISSN 1668-5180 Resistencia, Chaco. 
UDOLES: son los molisoles de las regiones húmedas y presentan un régimen údico. Tienen un horizonte superficial oscuro y rico en materia orgánica y prácticamente casi todos se encuentran bajo cultivo.

Mlac Argiudoles ácuicos: se los encuentra en áreas deprimidas o donde el drenaje no es tan rápido, como por ejemplo lomas bajas o pie de lomas. Son los denominados anteriormente suelos Brunizems hidromórficos y se los destina a cultivos agrícolas de maíz y trigo. (Cfr. INTA, 1990)

\section{Aptitud del Suelo:}

Conocer el comportamiento o la aptitud de los suelos para diferentes alternativas de uso significa valorar "[...] los efectos favorables y desfavorables de las distintas actividades posibles, en un contexto de producción sostenida y sin deterioro de los recursos naturales." (INTA, 1990: 59).

En el mapa de la figura $N^{\circ} 7$ se representó la aptitud de las tierras, clasificándolas o agrupando los distintos tipos de suelo en función a su capacidad para producir cultivos, pasturas y árboles maderables. De esta manera, se identifican las tierras aptas para agricultura, ganadería o forestación.

En el caso del Departamento General Obligado se advierten las siguientes capacidades de uso de la tierra:

\section{Aptitud ganadera agrícola:}

Se ubica en una franja con orientación Norte-Sur en el centro del departamento, constituyéndose en la única área con aptitudes agrícolas, en la que se cultivan aquellas especies adaptadas a las condiciones climáticas imperantes y que requieren de una alternancia de períodos con pasturas o actividades ganaderas.

\section{Aptitud ganadera:}

Son tierras aptas para la producción de pasturas naturales o implantadas y se las localiza en el resto del departamento, es decir, tanto en el occidente, como en la zona del valle de inundación del Río Paraná, al oriente. A su vez, la receptividad ganadera de los campos varía en función a diversos factores como lo son: el tipo de suelo, las condiciones de humedad, de anegamiento, el relieve, la pendiente, etc., que permiten la siguiente diferenciación:

- Tierras aptas para la producción de pasturas, con una receptividad ganadera de hasta un animal en 5 hectáreas, se registran en la franja de ancho variable correspondiente, principalmente, al valle de inundación del Paraná.

- Tierras aptas para la producción de pasturas, con una receptividad de hasta una unidad ganadera entre 5 y 10 hectáreas, son las que se ubican en el oeste o interior departamental.

\section{Uso del Suelo:}

"El suelo es el principal bien natural del que se dispone para cubrir las necesidades elementales, ya que en esta delgada capa de la corteza terrestre se asienta prácticamente toda la producción agropecuaria de la cual se obtienen alimentos y otras materias primas que satisfacen los requerimientos básicos de las personas." (CFA, 1995: 11) El uso o aprovechamiento que se hace del mismo varía a lo largo del espacio objeto de estudio. 
Figura No 7: Aptitud del suelo del Departamento General Obligado

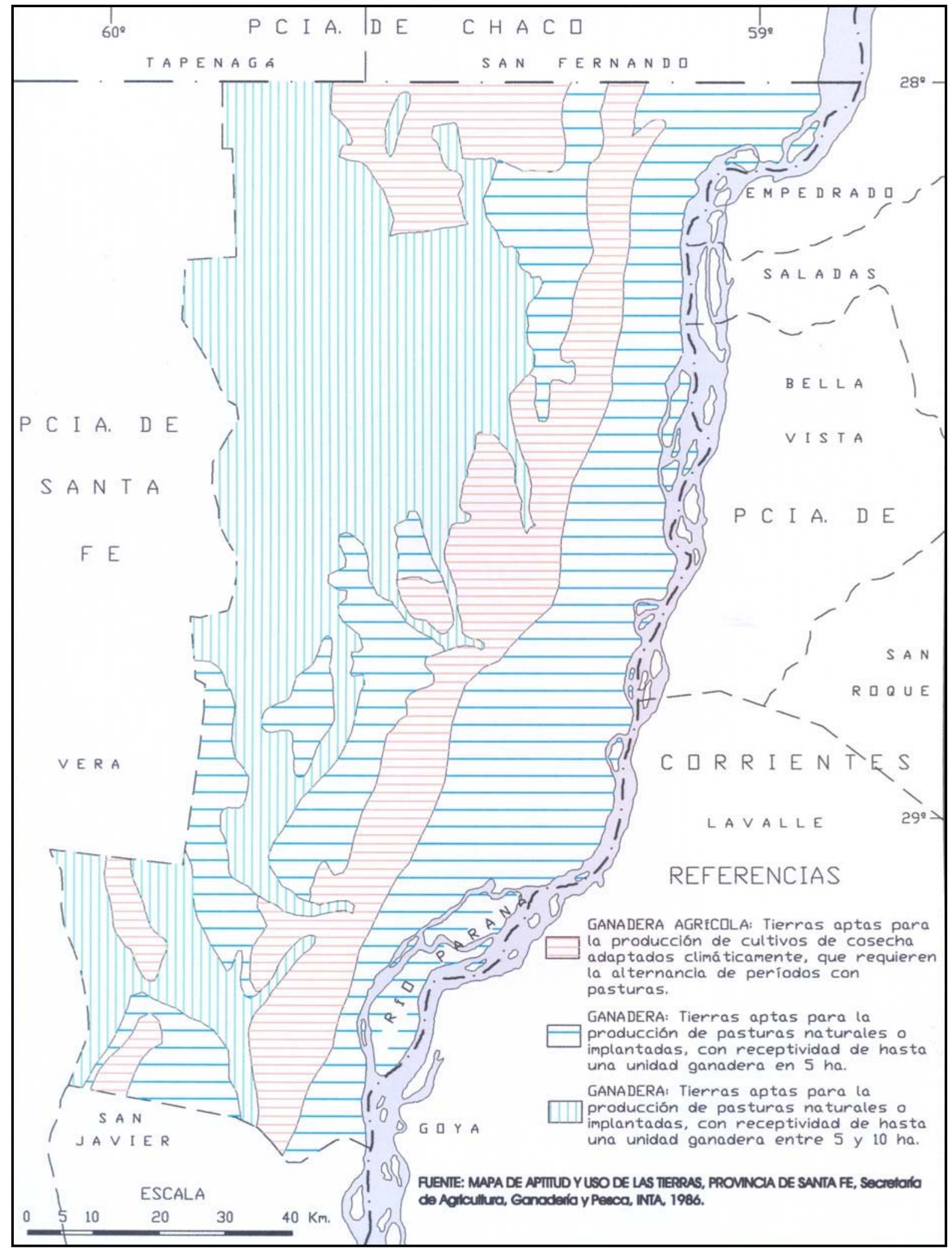

Publicado en formato digital: Prof. Patricia Perla Snaider y Prof. Néstor Eduardo Puig. ORDENAMIENTO ECOLÓGICO Y AMBIENTAL EN EL DEPARTAMENTO GENERAL OBLIGADO (Provincia de Santa Fe Argentina). Revista Geográfica Digital. IGUNNE. Facultad de Humanidades. UNNE. Año 12. No 24 . Julio Diciembre 2015. ISSN 1668-5180 Resistencia, Chaco. 
En nuestro país "[...] el criterio que rige el uso del suelo es la demanda internacional de productos agropecuarios" y "en consecuencia, no existe un ordenamiento territorial que paute un manejo integrado de los ecosistemas" (BERTONATTI y CORCUERA, 2000: 25).

Para abordar el análisis de esta variable se tuvieron en cuenta dos fuentes diferentes, mediante las que se interpretó el uso del suelo en distintas etapas cronológicas:

- El Mapa de Aptitud y Uso de las Tierras, Provincia de Santa $\mathrm{Fe}^{7}$ contiene información sobre el uso del suelo para el año 1986.

- Las Cartas de Imagen Satelital de la República Argentina ${ }^{8}$ fueron utilizadas para representar el uso del suelo para el año 1998.

\section{Uso del Suelo para el año 1986:}

Se advierte un predominio de tierras dedicadas a la ganadería, seguido por la actividad agrícola, y en una muy pequeña proporción aparece el monte natural asociado a la explotación pecuaria. El aprovechamiento de las tierras para la producción agrícola se produce en la franja contigua al área de inundación del valle del Paraná, mientras que en ésta última, se practica la cría de ganado bovino. En la fracción occidental del departamento el uso del suelo también es ganadero, complementado con la explotación del monte natural, tal como se advierte en la figura $N^{\circ} 8$.

\section{Uso del Suelo para el año 1998:}

Como ya se ha mencionado en la metodología de trabajo, este mapa de uso del suelo para el año 1998 (figura $N^{\circ}$ 9) ha sido elaborado en base a la diferenciación de áreas realizada con la información contenida en las Cartas de Imagen Satelital de la figura № 10. A partir de la distinción de dichas áreas, tales como la agrícola, vegetación natural, zonas cubiertas por bañados y aquellas correspondientes a los núcleos urbanos, se identificaron varios usos del suelo que se volcaron en el mapa de la figura $N^{0} 7$. De esta manera, se advirtieron los usos del suelo que se señalan a continuación:

- $\quad$ En el sector noroeste del departamento se observan áreas de vegetación natural surcadas por ríos y arroyos que la atraviesan, en su mayoría, en dirección noroeste - sureste. El monte natural está destinado, en su gran mayoría a la actividad pecuaria, aunque en algunos sectores se lo explota para la extracción de especies forestales, cuyos destinos varían entre la elaboración de insumos para industrias locales, la producción de carbón vegetal, su consumo como leña en industrias y hogares y/o su utilización para la construcción de postes. También es ganadero el uso de la tierra que se realiza en los valles de inundación de los ríos y arroyos que traspasan el sector ya mencionado.

\footnotetext{
7 Mapa de Aptitud y Uso de las Tierras Provincia de Santa Fe (1986) Instituto Nacional de Tecnología Agropecuaria, Secretaría de Agricultura, Ganadería y Pesca, Proyecto Arg 85/019, Área Edafología.

${ }^{8}$ Carta de Imagen Satelitaria de la República Argentina No: 2960-II Bella Vista, 2960-III Vera y 2960-IV Goya. Instituto Geográfico Nacional (ex Militar), Ejército Argentino, escala 1:250.000, datos relevados entre los años 1993 y 1998.
} 
Figura Nº 8: Uso del suelo para el año 1986 en el Departamento General Obligado

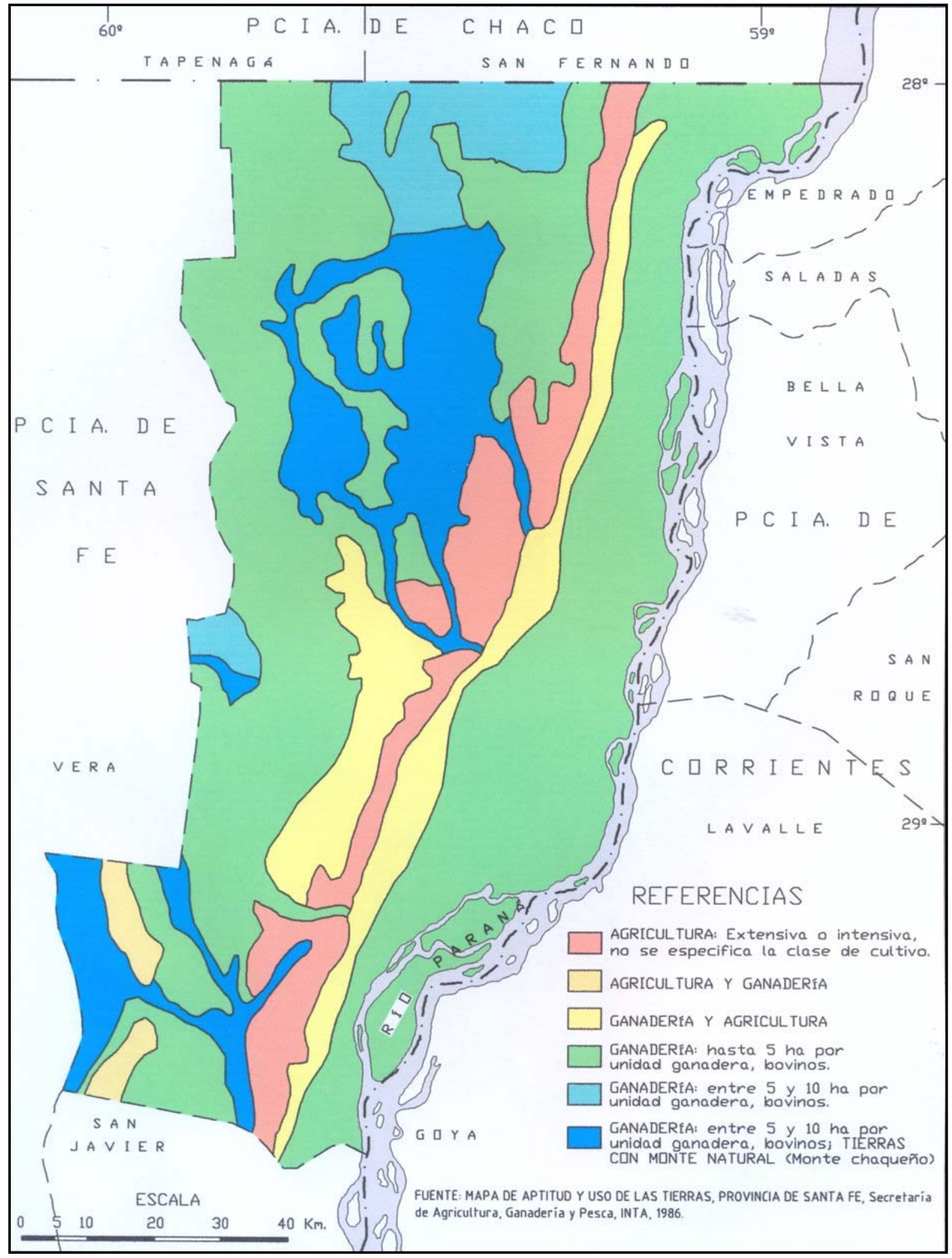

Publicado en formato digital: Prof. Patricia Perla Snaider y Prof. Néstor Eduardo Puig. ORDENAMIENTO ECOLÓGICO Y AMBIENTAL EN EL DEPARTAMENTO GENERAL OBLIGADO (Provincia de Santa Fe Argentina). Revista Geográfica Digital. IGUNNE. Facultad de Humanidades. UNNE. Año 12. No 24 . Julio Diciembre 2015. ISSN 1668-5180 Resistencia, Chaco. 
Figura Nº 9: Uso del suelo para el año 1998 en el Departamento General Obligado

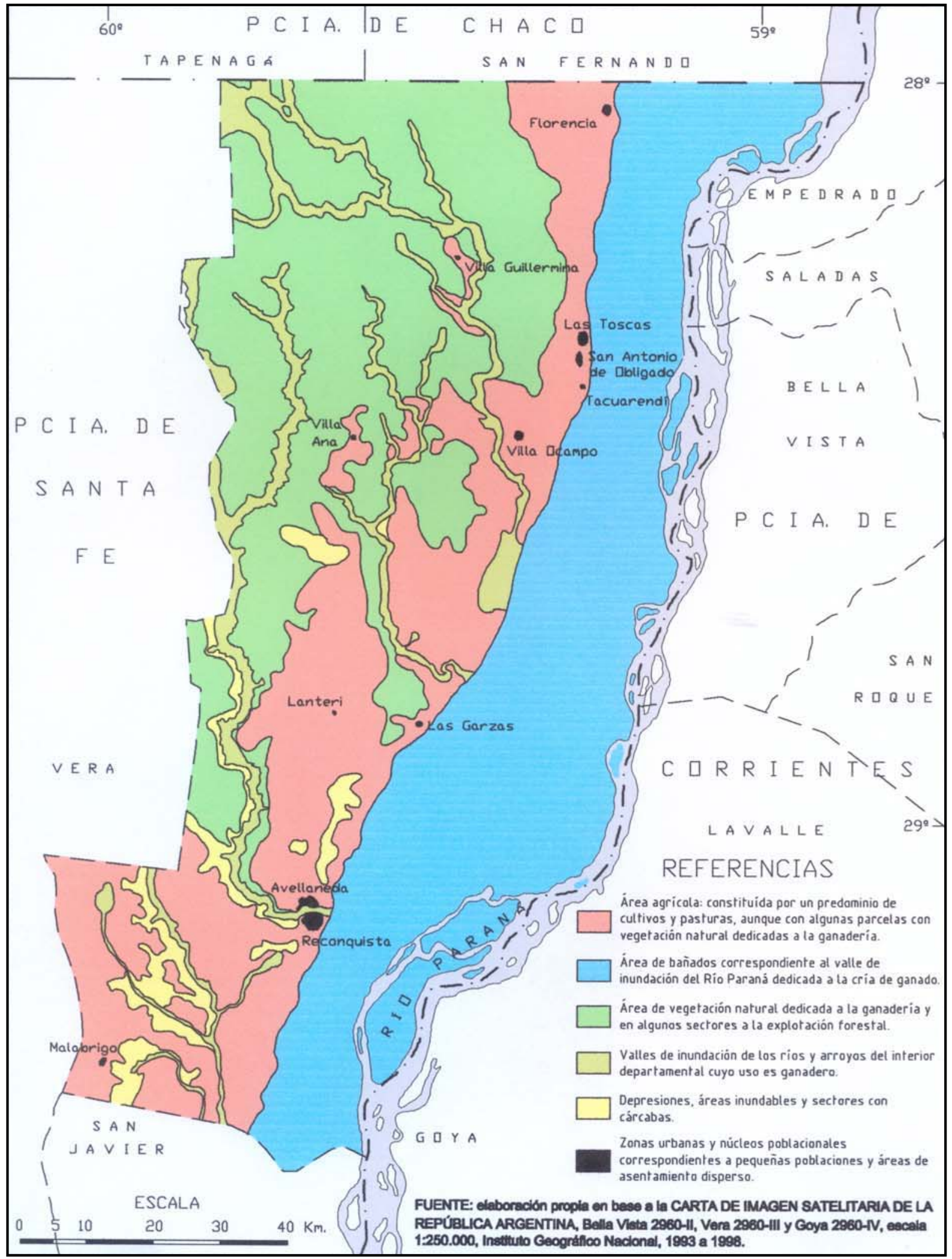

Publicado en formato digital: Prof. Patricia Perla Snaider y Prof. Néstor Eduardo Puig. ORDENAMIENTO ECOLÓGICO Y AMBIENTAL EN EL DEPARTAMENTO GENERAL OBLIGADO (Provincia de Santa Fe Argentina). Revista Geográfica Digital. IGUNNE. Facultad de Humanidades. UNNE. Año 12. № 24. Julio Diciembre 2015. ISSN 1668-5180 Resistencia, Chaco. 
Figura No 10: Carta de imagen satelitaria del Departamento General Obligado

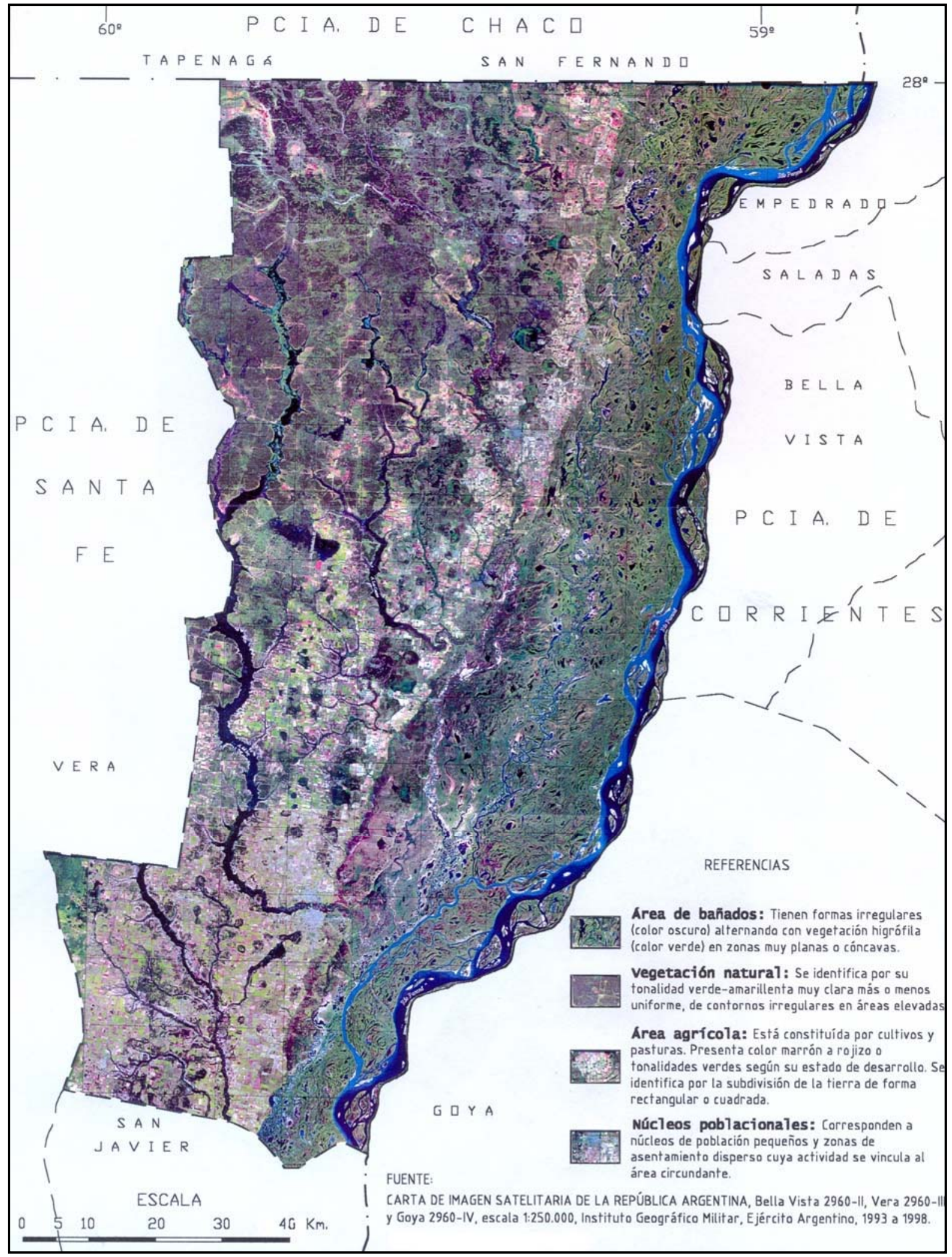

Publicado en formato digital: Prof. Patricia Perla Snaider y Prof. Néstor Eduardo Puig. ORDENAMIENTO ECOLÓGICO Y AMBIENTAL EN EL DEPARTAMENTO GENERAL OBLIGADO (Provincia de Santa Fe Argentina). Revista Geográfica Digital. IGUNNE. Facultad de Humanidades. UNNE. Año 12. No 24 . Julio Diciembre 2015. ISSN 1668-5180 Resistencia, Chaco. 
- En una franja orientada en sentido meridiano (Norte - Sudoeste) que atraviesa el centro del departamento, y cuyo ancho varía aumentando su espesor hacia el sur, se distribuye el área agrícola. En ella existe una preponderancia de cultivos de caña de azúcar, soja y algodón, a los que se están incorporando las plantaciones de sorgo, maíz, girasol, trigo y diversas forrajeras destinadas al consumo de los bovinos. Algunas parcelas situadas entre los campos de cultivos son destinadas a la cría de ganado.

- El área que se encuentra en el oriente, entre la franja agrícola y el cauce del Paraná, es el valle de inundación de dicho río y sólo puede ser aprovechada como uso ganadero, ya que las periódicas crecientes y el consecuente anegamiento no permite su utilización agrícola. Por otra parte, durante el período de crecida de las aguas se pierden innumerables cabezas de ganado, ya sea por la falta de pasturas al estar casi totalmente cubiertas por agua o porque mueren al tratar de ser rescatadas hacia las zonas "secas".

- $\quad$ Por último se identificó un uso del suelo urbano, comprendido por pequeños núcleos poblacionales que se distribuyen en el área agrícola y están en directa relación con sus actividades.

\section{RESULTADOS: ORDENACIÓN ECOLÓGICA Y AMBIENTAL}

La palabra sostenibilidad adquiere significación a partir de la publicación de "Nuestro Futuro Común" realizado por la Comisión Mundial sobre el Medio Ambiente y el Desarrollo (Comisión Brundtland) en el año 1987 (Cfr. MITCHELL, 1999: 45). "La Comisión, presidida por G. H. Brundtland, presentó su célebre informe [...] el cual hizo mucho por imponer la referencia al 'desarrollo sustentable', como nuevo elemento del lenguaje internacional y también de preocupación en los trabajos de los expertos de las organizaciones internacionales". (CFA, 1995). La definición que le otorgó la Comisión Mundial del Medio Ambiente y Desarrollo -CMMAD- al término "desarrollo sustentable" es la de "[...] satisfacer las necesidades básicas y las aspiraciones de bienestar de la población, sin comprometer la posibilidad de las generaciones futuras de satisfacer sus propias necesidades $y$ aspiraciones"9. Es decir que se trata de conseguir un uso racional de los recursos naturales, manteniendo, simultáneamente, una calidad de vida óptima para la población. Pero como todo el accionar del hombre se desarrolla sobre un determinado espacio geográfico, significa que indiscutiblemente su quehacer repercutirá directamente sobre los recursos naturales. Por tal razón, es necesario hacer un seguimiento de las consecuencias de este "accionar humano" para tratar de evitar que los impactos causados por el hombre lleguen a debilitar o agotar la capacidad de renovación del recurso natural (Cfr. ROMERO y SEPÚLVEDA, 1999: 3).

Entonces, considerando que el desarrollo sustentable de una región significa que los recursos sean utilizados de manera racional, se optó por relacionar el relieve y la vegetación con el tipo, la aptitud y el uso que se hace del suelo para determinar, de manera aproximada, la ordenación ecológica y ambiental de las tierras.

En el mapa de la figura $N^{\circ} 11$ se intenta representar un esbozo de ordenamiento socioeconómico -ambiental del Departamento General Obligado y se identifican los siguientes sectores:

\footnotetext{
${ }^{9}$ Comisión Mundial del Medio Ambiente y Desarrollo -CMMAD- (1987). Citado en: El Reto Ambiental del Desarrollo en América Latina y el Caribe (1990). Comisión Económica para América Latina y EI Caribe (CEPAL), Programa de las Naciones Unidas para el Medio Ambiente (PNUMA), Santiago de Chile, p. 14.
}

Publicado en formato digital: Prof. Patricia Perla Snaider y Prof. Néstor Eduardo Puig. ORDENAMIENTO ECOLÓGICO Y AMBIENTAL EN EL DEPARTAMENTO GENERAL OBLIGADO (Provincia de Santa Fe Argentina). Revista Geográfica Digital. IGUNNE. Facultad de Humanidades. UNNE. Año 12. No 24 . Julio Diciembre 2015. ISSN 1668-5180 Resistencia, Chaco. 
Figura $N^{0}$ 11: Mapa de Ordenamiento Socioeconómico-Ecológico del Departamento General Obligado.

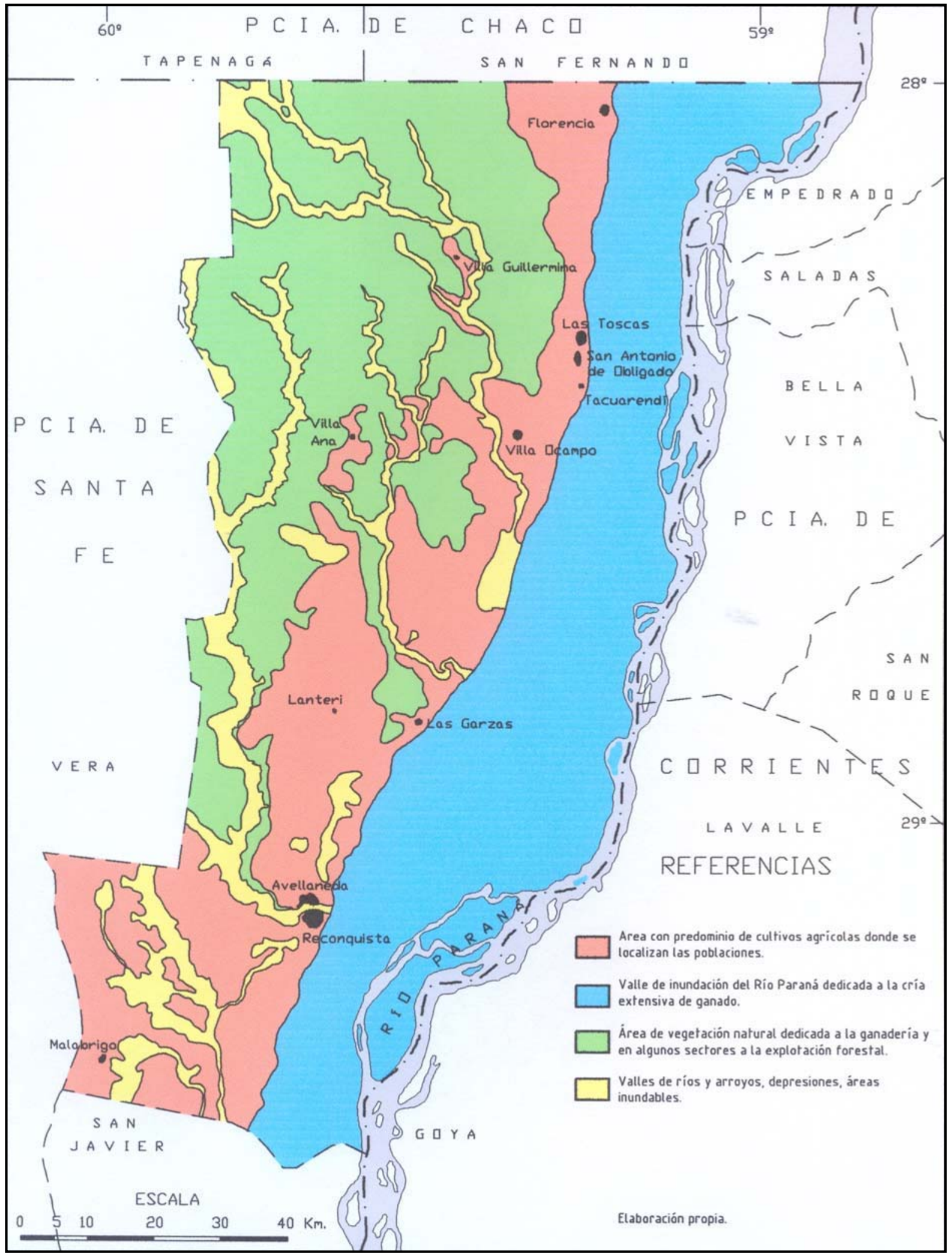

Publicado en formato digital: Prof. Patricia Perla Snaider y Prof. Néstor Eduardo Puig. ORDENAMIENTO ECOLÓGICO Y AMBIENTAL EN EL DEPARTAMENTO GENERAL OBLIGADO (Provincia de Santa Fe Argentina). Revista Geográfica Digital. IGUNNE. Facultad de Humanidades. UNNE. Año 12. No 24 . Julio Diciembre 2015. ISSN 1668-5180 Resistencia, Chaco. 
Revista Geográfica Digital. IGUNNE. Facultad de Humanidades. UNNE. Año 12. No 24. Julio - Diciembre 2015. ISSN 1668-5180 Resistencia, Chaco

1. Valle de inundación del Río Paraná dedicado a la cría extensiva de ganado: se ubica en el oriente departamental, el aprovechamiento que se hace de las tierras es pecuario y éstas son aptas para tales actividades pero con muy baja capacidad de carga debido a las periódicas inundaciones que sufre, razón por la cual tampoco existen poblaciones y la vegetación está adaptada a permanecer un período cubierta con agua: vegetación palustre de bañados y esteros.

2. Área con predominio de cultivos agrícolas donde se localizan las poblaciones: se localiza en el centro del departamento a lo largo de una franja con dirección norte-sur. Debido a que cuenta con suelos aptos para las actividades agrícolas tiene una diversidad de cultivos (caña de azúcar, algodón, soja, girasol, maíz, sorgo, etc.) y es el ámbito donde se asienta y se asentó la población.

3. Área de vegetación natural dedicada a la ganadería y en algunos sectores a la explotación forestal: en el occidente, en coincidencia con los bajos Submeridionales, se ubica el sector con vegetación natural compuesta por monte cerrado (mayormente ocupado por quebrachales) y palmares con pastizales. Se practica la actividad ganadera extensiva y no existen aglomeraciones de población, sino más bien población dispersa y muy escasa que se dedica al cuidado de los vacunos.

4. Valles de ríos y arroyos, depresiones y áreas inundables: a través de estrechas franjas atraviesan las 2 últimas áreas con dirección general NW-SE y se corresponden a los cauces de ríos y arroyos y las áreas inundables. Algunas poblaciones se asientan próximas a estos sectores ya que por ellos discurren ríos o arroyos necesarios para la población y las actividades económicas que ésta realice.

\section{RESULTADOS ESPERADOS}

El Ordenamiento Territorial (OT) se constituye en el proceso de organización del uso del suelo en función de sus características Ambientales y Sociales con la finalidad de promover el desarrollo sostenible.

Esperamos que el Ordenamiento Territorial del Departamento General Obligado de la Provincia de Santa Fe sea la base para la planificación ordenada del territorio, para el bienestar de las sociedades que viven en él y de las generaciones futuras.

En todo caso, este proceso no solo considera las mencionadas características, sino que trata de optimizarlas en la perspectiva de mejorar las condiciones de vida de la población considerando la demanda social y los condicionantes así como los determinantes de la misma.

\section{Desarrollo Socio-Económico.}

- Los Gobiernos, tanto provinciales como Municipales, contarán con información precisa para elaborar políticas agropecuarias apropiadas a diferentes situaciones; y finalmente una mayor recaudación fiscal.

- Los proyectos de desarrollo serán mejor dirigidos hacia espacios y/o producciones concretos.

- Las informaciones sobre el uso de la tierra, como así mismo información ambiental organizada sobre el modelo de ordenamiento territorial que aquí proponemos, estandarizado en bases de datos georreferenciados, estarán disponibles en tiempo y forma.

Publicado en formato digital: Prof. Patricia Perla Snaider y Prof. Néstor Eduardo Puig. ORDENAMIENTO ECOLÓGICO Y AMBIENTAL EN EL DEPARTAMENTO GENERAL OBLIGADO (Provincia de Santa Fe Argentina). Revista Geográfica Digital. IGUNNE. Facultad de Humanidades. UNNE. Año 12. No 24. Julio Diciembre 2015. ISSN 1668-5180 Resistencia, Chaco. 
Revista Geográfica Digital. IGUNNE. Facultad de Humanidades. UNNE. Año 12. № 24. Julio - Diciembre 2015. ISSN 1668-5180 Resistencia, Chaco

- Los productores podrán contar con la posibilidad de reorientar sus prácticas de manejo que atenúen el impacto ambiental y seleccionar los sitios a utilizar con las actividades agropecuarias más adecuadas a las reales posibilidades de sus tierras.

- Los potenciales inversores podrán obtener información sobre potencialidades y limitaciones ambientales para determinados negocios agropecuarios, con alta precisión de localización geográfica. Contarán con información que les permitirá, ajustar las tasaciones rurales a la realidad.

- Los asesores privados podrán tomar decisiones de trascendencia sobre aspectos ambientales y productivos en las empresas agropecuarias con mayor celeridad y precisión.

- Reducir la proporción de la población con necesidades básicas insatisfechas a través de un mejor aprovechamiento de las potencialidades del territorio.

- Evitar asentamientos espontáneos que no corresponden a los criterios más adecuados del Uso del Suelo y que pueden llevar a situaciones de riesgo así como vulnerabilidad.

- Lograr impactos positivos de la infraestructura en la rentabilidad agropecuaria

- Identificación de nuevas oportunidades de desarrollo; disminución del desempleo y mejoras en la calidad de vida en general.

\section{Mitigación de Impactos Ambientales}

- Las Evaluaciones y Auditorías de impacto ambiental se verán fortalecidas al disponer de mejores datos.

- Se podrá atenuar pérdidas en superficies agrícolas, rendimientos é infraestructura por mejor estimación de los impactos ambientales esperados.

- Especialmente se mejorará la definición de las áreas más aptas para sistemas productivos específicos según la potencialidad de los recursos naturales puestos en juego.

- Será más factible prevenir y en consecuencia mitigar los riesgos ambientales.

- Mejorar la resolución de conflictos generados por el uso de los recursos naturales (agua, suelos, flora, fauna).

- También será factible mitigar la degradación Ambiental; la perdida de áreas agrícolas con alto valor económico; compactación y erosión del suelo; pérdida de materia orgánica del suelo; degradación de la calidad del agua; incendios forestales y la degradación de bosques nativos.

\section{Avance del conocimiento Científico}

- Desarrollo y aplicación de metodologías ajustadas y sistematizadas de la evaluación de los recursos naturales, basados en sistemas de información geográfica y teledetección espacial.

- Delimitación, análisis geográfico y caracterización de futuras áreas de conservación o de uso y manejo restringido.

- Aplicación de metodología probada y validada, para realizar inventarios de uso actual de la tierra integrando teledetección, y redes de encuestas locales. 
Revista Geográfica Digital. IGUNNE. Facultad de Humanidades. UNNE. Año 12. № 24. Julio

- Diciembre 2015. ISSN 1668-5180 Resistencia, Chaco

- Recolección y sistematización de información precisa y actualizada, lo que puede favorecer ciertas líneas de financiamiento para nuevos proyectos de investigación o consolidar a los existentes.

\section{BIBLIOGRAFÍA}

APN - FVSA (2007): "Las Áreas Protegidas de la Argentina". Administración de Parques Nacionales Fundación Vida Silvestre Argentina. Buenos Aires, Septiembre 2007.

BERTONATTI, C. (2009): "La Naturaleza de la Patria". Ministerio de Educación, Buenos Aires, Diciembre 2009.

BERTONATTI, C. y J. CORCUERA (2000): "Situación Ambiental Argentina 2000". Fundación Vida Silvestre Argentina, Buenos Aires.

BIASUTTI, R. y ADRSSONE, R. (1957): "Dos Escritos Metodológicos de Ecogeografía". Serie Método de la Geografía N², Instituto de Geografía, Facultad de Filosofía y Letras, Universidad de Buenos Aires, Buenos Aires, 63 p.

BRUNIARD, E. (1979): El Gran Chaco Argentino - Ensayo de Interpretación Geográfica, Geográfica 4, Facultad de Humanidades, UNNE, Resistencia.

BRUNIARD, E. (1987): "Geografía del Nordeste Argentino". SENOC. Buenos Aires.

CANOBA, C. (1981): "Interpretación visual con imágenes MSS LANDSAT aplicadas a un sector del territorio santafesino". En: Estudios de Geografía de la Provincia de Santa Fe. Sociedad Argentina de Estudios Geográficos (GAEA), Serie especial № 9, Buenos Aires, pp. 49-58.

CEPAL. (1990): "El Reto Ambiental del Desarrollo en América Latina y el Caribe". Comisión Económica para América Latina y el Caribe (CEPAL), Programa de las Naciones Unidas para el Medio Ambiente (PNUMA), Santiago de Chile, Julio de 1990.

CERANA, L. (1960): "Suelos de la fracción norte de los bajos submeridionales de la provincia de Santa Fe" (Comunicación). En: IDIA Suplemento $N^{\circ}$ 1, Año 1960, INTA, Secretaría de Agricultura y Ganadería de la Nación, Buenos Aires, pp. 180-182.

CFA (1995): "El Deterioro de las Tierras en la República Argentina". La Secretaría de Agricultura, Ganadería y Pesca y el Consejo Federal Agropecuario en Alerta Amarillo, Consejo Federal Agropecuario, Buenos Aires.

CODES de PALOMO, I. (1993): "Ecogeografía: La complejidad del medio ambiente". Colección Geográfica (Dirección: Dr. Ricardo Capitanelli), Editorial CEYNE, Argentina, 128 p.

D’ENTREMONT, A. (1997): “Geografía Económica”. Ediciones Cátedra. Madrid. 567 p.

ESPINO, L., SEVESO, M. Y SABATIER, M. (1983): "Mapa de Suelos de la Provincia de Santa Fe". Ministerio de Agricultura y Ganadería de la Provincia de Santa Fe (MAG), Instituto Nacional de Tecnología Agropecuaria (INTA) E.E.R.A. Rafaela, Santa Fe, Argentina.

GAEA (1981): "Estudios de Geografía de la Provincia de Santa Fe". Sociedad Argentina de Estudios Geográficos, Serie Especial N 9, Rosario, 361 p.

FORMAN, R. y M. GODRON (1986): “Landscape Ecology”. John Wiley, New York. 619 p.

Publicado en formato digital: Prof. Patricia Perla Snaider y Prof. Néstor Eduardo Puig. ORDENAMIENTO ECOLÓGICO Y AMBIENTAL EN EL DEPARTAMENTO GENERAL OBLIGADO (Provincia de Santa Fe Argentina). Revista Geográfica Digital. IGUNNE. Facultad de Humanidades. UNNE. Año 12. No 24 . Julio Diciembre 2015. ISSN 1668-5180 Resistencia, Chaco. 
FRITSCHY, B. (Editora) (2000): "III Jornadas Nacionales de Geografía Física". Facultad de Ingeniería, Geoecografía y Medio Ambiente y Grupo de Estudio en Geografía Física, República Argentina, Universidad Católica de Santa Fe, Santa Fe, 23-27 de mayo de 2000.

GARCÍA-PELAYO y GROSS (1992): "Pequeño Larousse Ilustrado". Ediciones Larousse, Madrid, Impreso en Santa Fe de Bogotá, Colombia.

GOBIERNO DE SANTA FE (2007): "Zonificación del Bosque Nativo sobre la parcela rural de la Provincia de Santa Fe". Secretaría de Estado de Medio Ambiente y Desarrollo Sustentable. Servicio de Catastro e Información Territorial. En internet: http://www.santafe.gov.ar/index.php/web/content/view/full/39920

GRINZBURG, R. y J. ADÁMOLI (2005): “La Situación Ambiental Argentina 2005”. Fundación Vida Silvestre Argentina. Capítulo: "Situación Ambiental en el Chaco Húmedo".

GUÍA TURÍSTICA YPF (1996): "Mesopotamia y Noreste”. Año I, Número 4, Editorial Antártida S.A.C.I.F.E., Editorial San Telmo S. A, Buenos Aires, Argentina.

INTA (1990): "Atlas de Suelo de la República Argentina". Centro de Investigaciones de Recursos Naturales, Instituto Nacional de Tecnología Agropecuaria, Secretaría de Agricultura, Ganadería y Pesca, Proyecto PNUD ARG. 85/019. Escala 1:500.000 y 1:1.000.000, Tomos I y II, pp. 13-35 у $467-495$

IRONDO, M. (2007): "El Chaco Santafecino Neógeno y Geomorfología". Comunicaciones del Museo Provincial de Ciencias Naturales "Florentino Ameghino". Santa Fe.

KÜCHLER, A. Y I. ZONNEVELD (1988): “Vegetation mapping”. Handbook of Vegetation Science. Kluwer Academic Publishers. Boston. Vol. 10. 635 p.

LEFF, E. (Coordinador) (2000): "Los problemas del conocimiento y la perspectiva ambiental del desarrollo". Siglo veintiuno editores, Segunda edición, México, 409 pp.

MACHADO, L. (1998): "Satélites sobre la Pampa Húmeda". En: Revista Super Campo, de la Huerta a la Estancia. Año IV, № 41, Febrero de 1998, Editorial PERFIL, pp. 122-127.

MITCHELL, B. (1999): "La Gestión de los Recursos y del Medio Ambiente". Universidad de Waterloo, Ontario. Ediciones Mundi - Prensa, Madrid, 290 p.

MONTENEGRO, R. (1995): "Introducción a la Ecología y la Gestión Ambiental". Maestría en Gestión Ambiental y Ecología, Facultad de Arquitectura y Urbanismo - Facultad de Ciencias Exactas y Naturales y Agrimensura, Universidad Nacional del Nordeste, Resistencia - Corrientes.

MORELLO, J. (1970): "Modelo de relaciones entre pastizales y leñosas colonizadoras en el Chaco argentino". IDIA, 276: 31-52.

MORELLO, J. y J. ADÁMOLI (1974): "Las grandes unidades de vegetación y ambiente del Chaco Argentino". Segunda parte: Vegetación y ambiente de la provincia del Chaco. Serie Fitogeográfica $\mathrm{N}^{\circ}$ 13. I.N.T.A., Buenos Aires. 129 p.

NARBONA, C. (1999): "Agricultura y medio ambiente". Colección Desafíos de Nuestro Tiempo. Galaxia Gutenberg, Círculo de Lectores, Barcelona (España), pp. 5-23.

PINILLA, C. (1995): "Elementos de Teledetección". Editorial RA-MA, Madrid, 313 p.

ROMERO, S. y S. SEPÚLVEDA. (1999): "El desarrollo sostenible de la agricultura: el potencial de la era digital". Cuaderno Técnico $\mathrm{N}^{\circ} 13$, Instituto Interamericano de Cooperación para la

Publicado en formato digital: Prof. Patricia Perla Snaider y Prof. Néstor Eduardo Puig. ORDENAMIENTO ECOLÓGICO Y AMBIENTAL EN EL DEPARTAMENTO GENERAL OBLIGADO (Provincia de Santa Fe Argentina). Revista Geográfica Digital. IGUNNE. Facultad de Humanidades. UNNE. Año 12. № 24 . Julio Diciembre 2015. ISSN 1668-5180 Resistencia, Chaco. 
Revista Geográfica Digital. IGUNNE. Facultad de Humanidades. UNNE. Año 12. № 24. Julio - Diciembre 2015. ISSN 1668-5180 Resistencia, Chaco

Agricultura, Comité de Desarrollo Sustentable (CODES), Costa Rica. En Internet: http://infoagro.net/codes/stcpublicaciones.htm)

SÁNCHEZ, R. (2001): "Bases y Criterios Metodológicos para la Zonificación Ecológica y el Ordenamiento Ambiental del Territorio: aplicaciones al Partido de Tandil (Provincia de Buenos Aires)". En: Congreso Nacional sobre Problemáticas Sociales Contemporáneas, Facultad de Humanidades y Ciencias de la Universidad Nacional del Litoral. Santa Fe. Argentina.

SÁNCHEZ, R. (1989): "Zoneamento agroecologico: objetivos, conceitos centrais y aspectos metodológicos". 32 p. Fundação de Pesquisas Cândido Rondon. Cuiabá-MT, Brasil.

SÁNCHEZ, R. (2005): “Ordenación Ecológico-paisajística del Territorio: metodología, alcances geográficos y estudio de caso". Conferencia y publicación: Primeras Jornadas Argentinas de Ecología de Paisajes. GEPAMA-FADU/UBA. Buenos Aires. Argentina.

SÁNCHEZ, R. (2009): “Ordenamiento territorial. Bases y Estrategia Metodológica para abordar la Ordenación Ecológica y Ambiental de Tierras”. $1^{\circ}$ Edición. 266 p. Orientación Gráfica Editora. Buenos Aires. Argentina.

SÁNCHEZ, R. y M. NUÑEZ (2004): "El sistema de Tandilia: una aproximación a la definición de su espacialidad y compartimentación territorial." En Segundo Congreso de la Ciencia Cartográfica y IX Semana Nacional de Cartografía. Pp. 311-322. Buenos Aires. Argentina.

SÁNCHEZ, R., G. MATTUS y L. ZULAICA (1999): "Compartimentación Ecológica y Ambiental del Partido de Tandil (Provincia de Buenos Aires)". En: "Ambiental '99". San Juan. Argentina.

SANTOS, M. (1996): “A Natureza do Espaço”. São Paulo. Hucitec.

SEPÚLVEDA, S. y S. CHINCHILLA (1998): "Gestión sostenible de los espacios rurales sistema de información". Cuaderno Técnico Nº 6, Comité de Desarrollo Sustentable (CODES), Costa Rica. En Internet: http://infoagro.net/codes/stcpublicaciones.htm

TRUCO GRECO, C. (1968): ¡Los Mapas, breve historia del mundo y su imagen". Editorial Universitaria de Buenos Aires, Buenos Aires, Argentina, pp. 57-58.

Publicado en formato digital: Prof. Patricia Perla Snaider y Prof. Néstor Eduardo Puig. ORDENAMIENTO ECOLÓGICO Y AMBIENTAL EN EL DEPARTAMENTO GENERAL OBLIGADO (Provincia de Santa Fe Argentina). Revista Geográfica Digital. IGUNNE. Facultad de Humanidades. UNNE. Año 12. № 24 . Julio Diciembre 2015. ISSN 1668-5180 Resistencia, Chaco. 